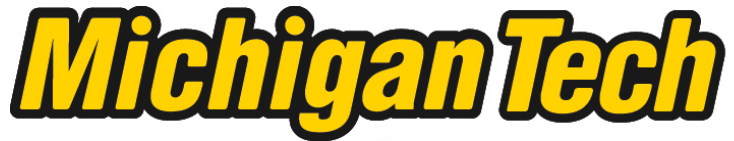 \\ Michigan Technological University Create the Future Digital Commons @ Michigan Tech
}

Dissertations, Master's Theses and Master's Reports - Open

Dissertations, Master's Theses and Master's

Reports

2013

FACTORS AFFECTING DIPOREIA GROWTH RATES IN LAKE SUPERIOR

Miles J. Corcoran

Michigan Technological University

Follow this and additional works at: https://digitalcommons.mtu.edu/etds

Part of the Biology Commons

Copyright 2013 Miles J. Corcoran

\section{Recommended Citation}

Corcoran, Miles J., "FACTORS AFFECTING DIPOREIA GROWTH RATES IN LAKE SUPERIOR", Master's Thesis, Michigan Technological University, 2013.

https://doi.org/10.37099/mtu.dc.etds/587

Follow this and additional works at: https://digitalcommons.mtu.edu/etds

Part of the Biology Commons 
FACTORS AFFECTING DIPOREIA GROWTH RATES IN LAKE SUPERIOR

By

Miles J. Corcoran

\begin{abstract}
A THESIS
Submitted in partial fulfillment of the requirements for the degree of MASTER OF SCIENCE In Biological Sciences
\end{abstract}

MICHIGAN TECHNOLOGICAL UNIVERSITY

2013

(C) 2013 Miles J. Corcoran 

This thesis has been approved in partial fulfillment of the requirements for the Degree of MASTER OF SCIENCE in Biological Sciences.

\title{
Department of Biological Sciences
}

\author{
Thesis Advisor: Dr. Nancy A. Auer \\ Committee Member: Dr. Martin T. Auer \\ Committee Member: Dr. Rupali Datta
}

Department Chair: Dr. Chandrashekhar P. Joshi 



\section{Table of Contents}

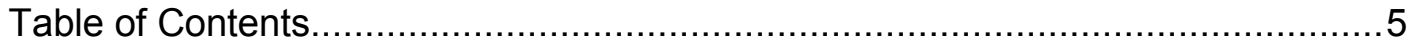

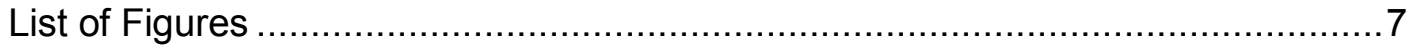

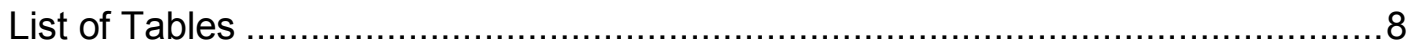

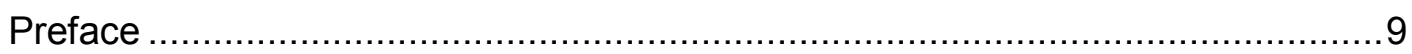

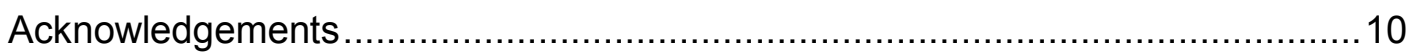

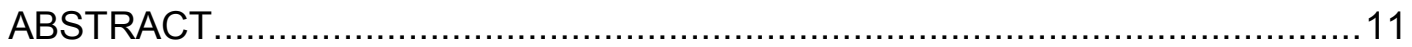

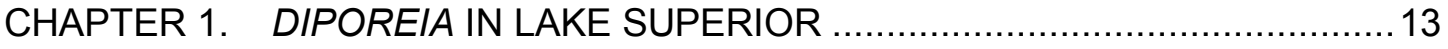

INTRODUCTION

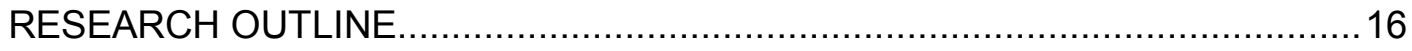

ABUNDANCE OF DIPOREIA AND OTHER MACROINVERTEBRATES .............17

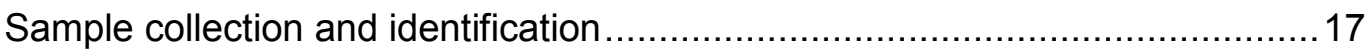

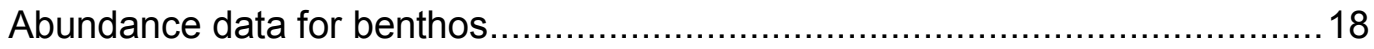

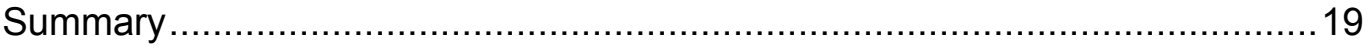

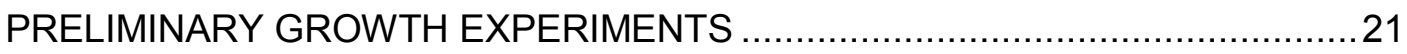

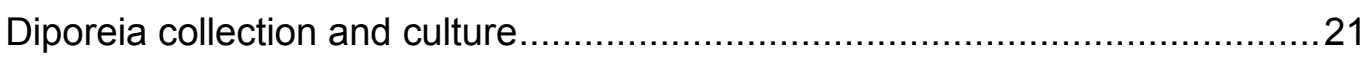

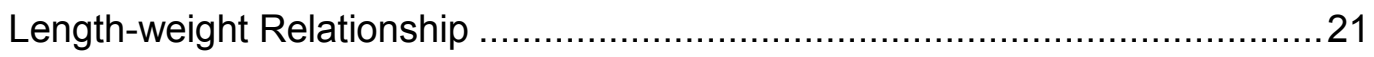

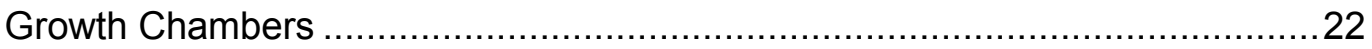

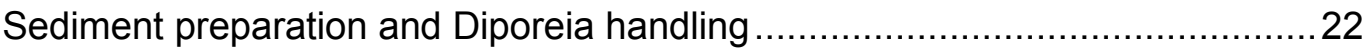

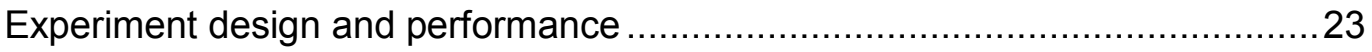

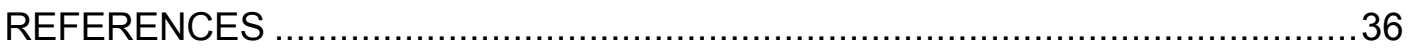

CHAPTER 2. Measurement of Lake Superior Diporeia Respiration Using

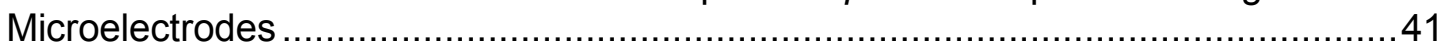

ABSTRACT

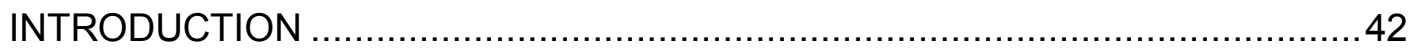

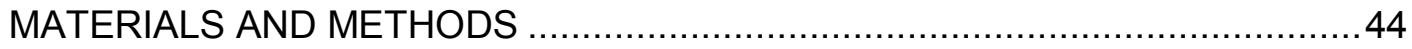

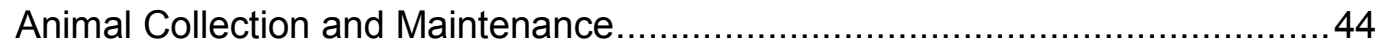

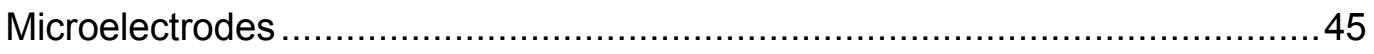

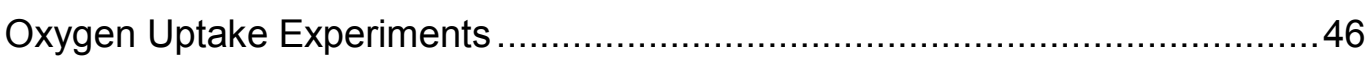

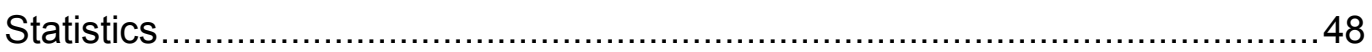

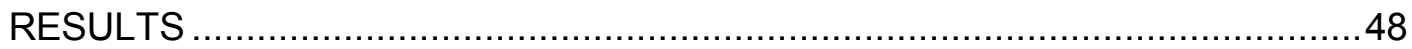

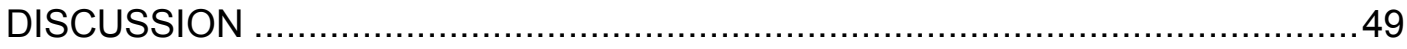

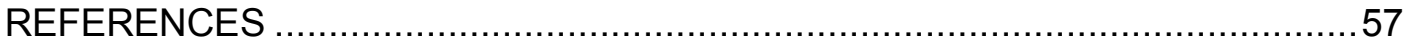


CHAPTER 3. Measuring the Effects of Food Availability on Lake Superior Diporeia Consumption Rates Using Radiolabeled Algae .................................. 61

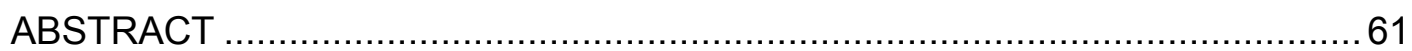

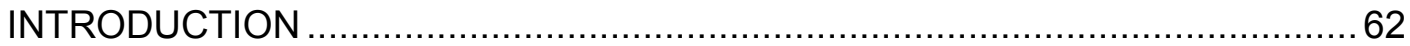

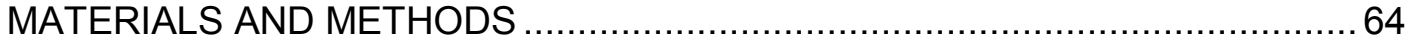

Collection and Maintenance of Benthic Communities .................................... 64

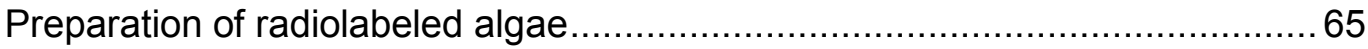

Determining specific activity of radiolabeled algae ..................................6 66

Assessing consumption through radioisotope content ..............................6 67

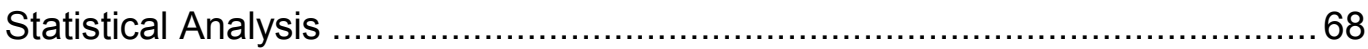

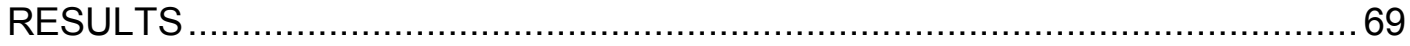

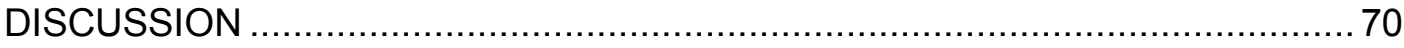

Overall model performance and assessment ....................................... 70

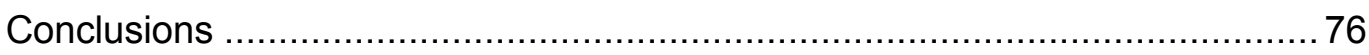

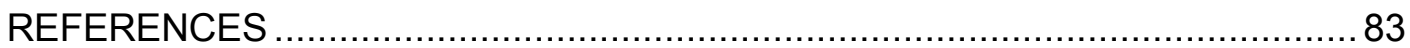




\section{List of Figures}

Figure 1.1 Mean abundances ( \pm SE) of Diporeia on the shelf, slope, and profundal regions of Lake Superior during spring, summer and fall of a) 2011 and b) 2012.

Figure 1.2 Diporeia length-frequencies for the shelf, slope, and profundal regions of Lake Superior during spring 2011.

Figure 1.3 Diporeia length-frequencies for the shelf, slope, and profundal regions of Lake Superior during summer 2011.

Figure 1.4 Diporeia length-frequencies for the shelf, slope, and profundal regions of Lake Superior during fall 2011.

Figure 1.5 Diporeia length-frequencies for the shelf, slope, and profundal regions of Lake Superior during spring 2012.

Figure 1.6 Diporeia length-frequencies for the shelf, slope, and profundal regions of Lake Superior during summer 2012.

Figure 1.7 Diporeia length-frequencies for the shelf, slope, and profundal regions of Lake Superior during fall 2012.

Figure 1.8 A length-weight relationship for Diporeia taken from Lake Superior on 5 October $2011(n=59)$.

Figure 2.1 Observed dissolved oxygen (DO) concentrations over time during a control trial (i.e. no test animals in microcosm). The decrease in DO concentration during the first 1.25 hours is due to oxygen contained within the electrolyte being reduced by the cathode.

Figure 2.2 Relationship between Diporeia body length and mass-specific respiration $\left(\mathrm{mgO}_{2} \cdot \mathrm{gDW}^{-1} \cdot \mathrm{d}^{-1}\right)$. Animal size was shown to have no significant relationship with respiration rate $(p=0.16)$.

Figure 3.1 Relationship between the average disintegrations per minute (DPM) per milligram of algal carbon and time ( \pm SE) for three cultures of green algae ( $S$. capricornutum) inoculated with $\mathrm{NaH}^{14} \mathrm{CO}_{3}$ at an activity of $0.1 \mu \mathrm{Ci} \cdot \mathrm{mL}^{-1}$.

Figure 3.2 Relationship between the measured turbidity of a sample $(n=17)$ of green algae (S. capricornutum) and its particulate organic carbon content (POC).

Figure 3.3 Observed consumption rates from feeding trials during June and July 2013 using radiolabeled S. capricornutum and either one (1D=circles) or five $(5 \mathrm{D}=$ diamonds) Diporeia. Open shapes denote outliers. (a) All values from 5D trials plotted with means of 1D trials. (b) Nonlinear model (dashed line represents 95\% confidence interval) showing the relationship between consumption rate (mean $\pm S E$ ) and organic carbon flux $\left(J_{P O C}\right)$.

Figure 3.4 Linear relationship for Diporeia consumption rates $( \pm S E)$ within the natural range $(<350)$ of organic carbon fluxes $\left(\mathrm{J}_{\mathrm{POC}}\right)$ in the Great Lakes. The vertical dashed lines correlate to literature values for $\mathrm{J}_{\mathrm{POC}}$ in the each of the Great Lakes (Meyers 1980; Bloesch 1982; Charlton 1983; Baker 1991; Meyers and Eadie 1993; Urban et al. 2004). $\left(R^{2}=0.91, p<0.0001\right)$ 


\section{List of Tables}

Table 1.1 Mean abundance and biomass of the four most prominent benthic invertebrates during 2011 and 2012. Values represent the mean ( \pm SE) of 53 PONAR grabs collected from the shelf, slope, and profundal regions along the western edge of the Keweenaw Peninsula in Lake Superior.

Table 1.2 Mean abundances (individuals $\cdot \mathrm{m}^{-2}$ ) of benthos in the shelf, slope, and profundal regions of Lake Superior during 2011.

Table 1.3 Mean abundances (individuals $\cdot \mathrm{m}^{-2}$ ) of benthos in the shelf, slope, and profundal regions of Lake Superior during 2012.

Table 2.1 Respiration rates for three size classes (mean body length \pm mean $\mathrm{SE}$ ) of Lake Superior Diporeia based on $\mathrm{O}_{2}$ depletion and the total dry weight of all individuals in each trial.

Table 2.2 Comparison of literature values for the respiration rate $\left(\mathrm{mgO}_{2} \cdot \mathrm{gDW}^{-1} \cdot \mathrm{d}^{-1}\right)$ of juvenile Diporeia (mean dry weight of $1.6 \mathrm{mg}$ ).

Table 3.1 Parameter estimates for six equations predicting Diporeia consumption $\left(\mathrm{mgC} \cdot \mathrm{gDW}^{-1} \cdot \mathrm{d}^{-1}\right)$ from food availability (i.e. organic carbon flux; $\mathrm{J}_{\mathrm{POC}}$ ). The linear models (a) predict consumption at low $J_{P O C}$ values, while the nonlinear models (b) describe the response of consumption to food availability at high $\mathrm{J}_{\mathrm{Poc}}$ values. Parameter calculations were made for each model based on the experimental method used (i.e. individual and combined for 1D and $5 \mathrm{D}$ trials). 


\section{Preface}

This thesis is a description of the work I have conducted over the past two years under the supervision of my advisor, Dr. Nancy A. Auer. No portion of this thesis has previously been submitted for publication. All of the material in this manuscript is original, except for references that have been made towards previous studies. I worked in collaboration with Dr. Martin T. Auer, as well as my advisor, to develop the experimental methods presented in Chapter 2 and Chapter 3.

This project has been funded by the Environmental Protection Agency (GL00E00560/0). The microelectrodes used to measure Diporeia respiration were lent to me by Dr. Martin T. Auer. Training in the use of radioactive materials was performed through Michigan Technological University's Radiation Safety Program. The use of a radiation certified laboratory, along with specific procedures for radioisotope work, were provided by Dr. Martin T. Auer.

Chapter 2 and Chapter 3 will be submitted for publication in the near future. 


\section{Acknowledgements}

I would like to express my appreciation to a number of individuals who helped me during my time at Michigan Technological University.

First, I would like to thank Dr. Nancy Auer, my advisor, for her guidance, patience, and devotion. Your mentorship has been remarkable in helping me grow as a scientist and as an independent thinker. Despite your incredible work load, your door is never closed and your spirits are never discouraged. I thank you for providing me with this opportunity to earn my master's degree, preparing me for the past 2 years, and supporting me while writing my thesis. I cannot imagine a better fit as an advisor.

Special thanks are also extended to Dr. Marty Auer. You have worked tirelessly to help me improve the quality of work presented here and to hone my overall abilities as a professional. I greatly appreciate everything you have done to whip me into shape. Also, thank you to Dr. Rupali Datta for agreeing to serve on my committee and offer your suggestions.

I would like to thank the captain of the R/V Agassiz, Stephen Roblee, for always keeping us safe and for offering to help in any way possible when in the field. I enjoyed our countless conversations with topics ranging from boat operations to classic country artists. Additionally, thank you to the staff and personnel of both the Biology Department and the Civil and Environmental Engineering Department for their support and kindness. I especially thank Jeff Lewin and Dave Perram for being tremendous resources for all of my lab analyses.

I would also like to thank the following graduate and undergraduate students in the Auer research group for their help in the field, lab, and office, as well as for their friendship: Marcel Dijkstra, Ben Downer, Rachael Pressley, Konrad Roznik, and Rasika Gawde. To Emily Bouckaert, thank you for permitting me to use the camera scope. To Amanda Carlson, thank you for your support and understanding during the final year of my graduate career. To Jeff LaMuth and all of the members of Ridge Roamers and DiscoTech, thank you for keeping me sane.

Finally, and most importantly, my family. Mom and dad, you have always encouraged me to be as ambitious as possible, and you have helped guide me through many tough times. Thank you for your faith and support. 


\section{ABSTRACT}

An ability to predict population dynamics of the amphipod Diporeia is important in understanding how energy pathways in the Lake Superior food web might be altered by disturbances to the ecosystem. Estimating growth rates for this prominent prey item for fish requires information on the physiological effects of changes to its environment. These effects have been investigated for Diporeia in other Great Lakes, but little is known about Lake Superior populations. The primary objective of this study is to obtain quantitative data for rates of Diporeia respiration and consumption that can be incorporated into a bioenergetics model for Lake Superior. Benthic communities in Lake Superior were sampled bimonthly from April through September during 2011 and 2012 to investigate spatial and temporal trends of Diporeia abundances as well as size class structures of the population. Additional samples of Diporeia were collected and kept alive in natural sediment for laboratory experiments. Respiration rates for Diporeia were measured by monitoring dissolved oxygen concentrations in microcosoms using microelectrodes. Additionally, a series of experiments to estimate consumption rates based on food availability were conducted using ${ }^{14} \mathrm{C}$-labeled algae (Selenastrum capricornutum). Amphipod population densities are highest between 30-110 m (slope) compared to 0-30 m (shelf) or >110 m (profundal) regions in Lake Superior. This heterogeneous distribution of Diporeia in Lake Superior is an important component to quantifying lake-wide biomass. Rates of oxygen consumption by Diporeia range from 32.0 to $44.7 \mathrm{mgO}_{2} \cdot \mathrm{gDW}^{-1} \cdot \mathrm{d}^{-1}$, and do not vary significantly with body size per individual. The predicted consumption rate corresponding to average Lake Superior algal carbon fluxes was $0.08 \pm \mathrm{SE} \mathrm{mgC} \cdot \mathrm{gDW}^{-1} \cdot \mathrm{d}^{-1}$. Data on Lake Superior Diporeia biomass and 
bioenergetics found in this study can be incorporated in a model used to estimate the viability of this population under potential future environmental stressors. 


\section{CHAPTER 1. DIPOREIA IN LAKE SUPERIOR}

\section{INTRODUCTION}

The trophic dynamic aspect proposed by Lindeman (1942) was the first quantitative effort to define patterns of connectedness between energy supply and transfer in food webs. In this attempt to understand energy pathways, the lake ecosystem was expressed as a network of groups of organisms (i.e. tropic levels) connected by feeding (Golley 1993). The rate at which organisms assimilate food has since been used as an approach to develop ecosystem energy-flow models (Odum 1956; Kitchell et al. 1977; Rice and Cochran 1984). In order to understand the mechanisms through which pelagic and benthic nutrients are allocated to higher trophic levels, it is essential to investigate the factors affecting the energetics of primary consumers within a lake.

Lake Superior is the largest freshwater lake in the world by surface area, and perhaps the most pristine of the Laurentian Great Lakes (Strachan and Eisenreich 1988) due to its remote location. Nonetheless, this ecosystem has been subjected to numerous disturbances as local industry and land development continue to expand in the region. Specifically, trace metal and organic chemical contamination, along with the introduction of non-native species, have affected the interactions in biotic and abiotic cycles in Lake Superior (Galloway et al. 1982; Mills 1994; Nriagu 1995; Kitchell et al. 2000; Grigorovich 2003). The functionality of an ecosystem is influenced by a vast amount of physical and biological factors. Any attempt to predict the response of a system as large as Lake Superior requires a suite of models that have been validated and can be used in conjunction (Golley 1993). The 
overall aim of this research is to collect new data required to parameterize a bioenergetics model, which will later be incorporated into a more detailed and integrated model used to predict Lake Superior ecosystem responses to anthropogenic disturbances (e.g. invasive species, climate change, etc.). In an effort to increase the understanding of mechanisms contributing to Lake Superior ecosystem health and condition, the amphipod Diporeia spp was chosen as a focus organism to parameterize a bioenergetics model.

The shrimp-like organisms of the genus Diporeia spp., previously known as Pontoporeia (Bousfield 1989), are native to the cold, hypolimnetic waters of proglaciated lakes in North America. Historically, these amphipods have been widely distributed among all of the Laurentian Great Lakes, accounting for up to $70 \%$ of the macroinvertebrate biomass (Nalepa 1989). They are nutrient rich (i.e. lipids) organisms and are responsible for consuming up to $30 \%$ of organic matter that has settled to the lake bottom (Gardner et al. 1985). Recent studies (Pilgrim et al. 2009) have shown that populations of Diporeia spp. in the Great Lakes might include several distinct species. Consequently, they are typically referred to by their genus name, Diporeia spp (herein called Diporeia).

Diporeia are considered a keystone species in Lake Superior because of the major role they play in transporting organic carbon produced in the pelagic zone to benthic communities and to higher trophic levels (Auer et al. 2009). The efficiency with which Diporeia are able to transfer organic carbon makes them an important prey item within Lake Superior's ecosystem. Many fish species in Lake Superior favor Diporeia as a food source (Wells 1980; Kitchell et al. 2000; Scharold et al. 
2004). Among these, lake whitefish (Coregonus clupeaformis) is considered to be the most valued due to its role in commercial fisheries (Nalepa et al. 2005). Lake whitefish are a benthivorous species that preferentially feed on Diporeia (Rennie et al. 2009). Both whitefish and Diporeia populations are considered to be stable in Lake Superior (Scharold et al. 2004; Auer et al. 2009; Gorman et al. 2012), having biomass estimates within historical ranges. The whitefish - Diporeia pairing is thought to both limit and regulate the bulk of energy flow within the benthic component of Lake Superior's food web.

The stability of Diporeia populations within Lake Superior suggests that this lake has had fewer influences on the benthic community from ecological disturbances compared to other Great Lakes. Diporeia populations have undergone significant declines in Lakes Erie, Huron, Michigan, and Ontario since the early 1990's (Nalepa et al. 1998; Lozano et al. 2001; Lozano et al. 2003; Nalepa et al. 2006; Barbiero et al. 2011). It has been proposed that the introduction of invasive zebra and quagga mussels (Dreissena polymorpha and D. bugensis) is linked to Diporeia population declines in the lower Great Lakes (Landrum et al. 2000; Vanderploeg et al. 2002; Nalepa et al. 2006). Lake Superior is the only Great Lake that has not been subjected to widespread invasion by mussels. (Cook and Johnson 1974; Kraft 1979; Auer and Kahn 2004; Barbiero et al. 2011; Auer et al. 2013). Theories such as food limitation (dressenids outcompete Diporeia by filtering phytoplankton and detritus from the water column), toxic excretions (dressenid pseudofeces influence Diporeia survival rates), predation (dreissenid filtering results in clearer water, making Diporeia more vulnerable to predators), are among several 
others that have been offered to explain Diporeia population declines (Dermott 2001; Nalepa et al. 2006; Watkins 2007). None of these theories have been definitively shown to have an impact on Diporeia populations. Moreover, coexistence of dressenids and Diporeia has been documented in Cayuga Lake by Dermott et al. (2005).

The ability to accurately determine Diporeia respiration and consumption rates is not only an important component of modeling growth, but also has major influences on estimates of contaminant uptake and transfer. Diporeia are rich in lipids and therefore may accumulate large amounts of organic contaminants and heavy metals since these pollutants tend to concentrate in this type of fatty tissue. (Landrum and Nalepa 1998). Since Diporeia are a major food source for whitefish, alewife, rainbow smelt, bloaters, yellow perch, and sculpins (Scharold et al. 2004; Nalepa et al. 2006; Rennie et al. 2009), expanding our knowledge base of Diporeia metabolic processes is required to better understand the potential severity of destruction to aquatic food webs in the event of anthropogenic pollution and contamination.

\section{RESEARCH OUTLINE}

Empirical models (Strayer and Likens 1986; Rasmussen and Kalff 1987) have shown that macroinvertebrate biomass is directly related to phytoplankton production and deposition. Consequently, zoobenthos are typically used as a measure of biological integrity within freshwater systems (Fore et al. 1994). Growth rates and abundances of Diporeia have been selected as indicators of ecological health for all of the Great Lakes (Reynoldson 1993). Understanding the causes of 
subtle changes in Diporeia physiology (e.g. consumption and respiration rates) could have a significant utility in understanding their population dynamics.

A Diporeia bioenergetics model requires data on population size, food resource availability (i.e. organic carbon flux), environmental conditions of the lake, and physiological rates for growth calculations. The main focus of this research is an examination of Diporeia growth in Lake Superior. Current abundance estimates are presented here in CHAPTER 1 to establish the state of Diporeia population structure on temporal and spatial scales. In CHAPTER 1, preliminary experiments conducted to investigate growth rates based on changes in body length are described.

CHAPTER 2 and CHAPTER 3 are individual studies of Diporeia respiration and consumption, respectively. Sensitivity analyses of bioenergetics models have shown that these two physiological rates have the greatest influences on model predictions (Kitchell et al. 1977; Rice and Cochran 1984). These studies on respiration and consumption are seen as the fundamental basis on which to build a growth model. Environmental forcing conditions (e.g. water temperature, carbon deposition, etc.) for the model will be determined using output from the coupled hydrodynamic-water quality model.

\section{ABUNDANCE OF DIPOREIA AND OTHER MACROINVERTEBRATES}

\section{Sample collection and identification}

During 2011 and 2012, samples were collected aboard the R/V Agassiz during field monitoring cruises along a transect, known as Houghton North (HN), starting near the North Entry of the Keweenaw Waterway (Michigan, USA) and 
extending 26 km into Lake Superior (see Auer and Kahn 2004; Urban et al. 2005; Auer et al. 2009). A total of 53 PONAR (area $=0.046 \mathrm{~m}^{2}$ ) grabs were collected from $25 \mathrm{~m}, 50 \mathrm{~m}$, and $190 \mathrm{~m}$ during the spring, summer, and fall of each year. These stations represented shelf $(0-30 \mathrm{~m})$, slope $(30-110 \mathrm{~m})$, and profundal $(>110 \mathrm{~m})$ regions of the lake. Triplicate samples were taken at each station, except for the shelf during spring 2011 when only two samples were taken due to equipment malfunction and time constraints. PONAR grab samples were elutriated, sieved through a $243 \mu \mathrm{m}$ mesh net, and were preserved in $10 \%$ formalin. Benthic invertebrates were identified and counted following Auer and Kahn (2004). Diporeia lengths were measured following Quigley and Lang (1989). All individuals less than $2.5 \mathrm{~mm}$ were considered young of year (YOY), and they were assumed to have a length of $2 \mathrm{~mm}$ when calculating the average body size of all individuals within a sample.

\section{Abundance data for benthos}

The distribution of Diporeia between the three stations was consistent from 2011 to 2012 . Diporeia abundance (individuals $\cdot \mathrm{m}^{-2}$ ) was greatest in the slope region in both years, and the shelf and profundal regions did not differ significantly $(p<.001)$ in either year (Figure 1.1). The average body lengths for Diporeia among all samples ranged from 2.5 to $6.0 \mathrm{~mm}$. Size distributions for Diporeia in the shelf, slope, and profundal regions were shown by season in Figure 1.2, Figure 1.3, and Figure 1.4 for 2011, and in Figure 1.5, Figure 1.6, and Figure 1.7 for 2012.

Diporeia was the most abundant macroinvertebrate in 2011 and 2012, comprising $45.5 \%$ of the total number of organisms counted. The most abundant 
benthic groups after Diporeia, were nematodes, oligochaetes, sphaeriids, and chironomids, accounting for $19.1 \%, 14.5 \%, 9.9 \%$, and $5.5 \%$ of organisms, respectively. Average abundances of the four most prominent benthic groups (see Auer and Kahn 2004) in the Lake Superior macroinvertebrate communities are listed in Table 1.1. These abundances were multiplied by the average dry weight (estimates of organism biomass taken from Nalepa and Robertson 1981) of each organism to estimate the biomass. Average abundances $( \pm S E)$ for all benthos are listed in Table 1.2 for 2011, and Table 1.3 for 2012.

\section{Summary}

Although there was considerable variation among sample replicates, our results of macroinvertebrate abundances correspond to previous studies. The average annual Diporeia abundance found in this study was $1,607 \cdot \mathrm{m}^{-2}$ (Table 1.1). This estimate compares closely to the mean of $1,152 \cdot \mathrm{m}^{-2}$ found in 1998,1999 , and 2000 by Auer and Kahn (2004) and $1,450 \cdot \mathrm{m}^{-2}$ found in 2003 by Auer et al. (2009). In 2008, Barbiero et al. (2011) reported open lake (>90 m) Diporeia densities of $380 \cdot \mathrm{m}^{-}$ ${ }^{2}$, and nearshore $(30-90 \mathrm{~m})$ densities of $2,114 \cdot \mathrm{m}^{-2}$. All three of these studies show that populations of Diporeia in Lake Superior remain stable, and do not deviate from historical records. It has also been well documented that the benthic community of Lake Superior exhibits a pattern of elevated Diporeia abundances on the slope (30 to $125 \mathrm{~m}$ ) region of the lake (Cook 1975; Kraft 1979; Auer et al. 2013) compared to the shelf $(0$ to $30 \mathrm{~m})$ and profundal $(>125 \mathrm{~m})$ regions. Our data from samples collected near the Keweenaw Peninsula support this theory that regions of elevated densities, 
termed "The Ring of Fire" (Auer et al. 2013), exist in a band around the lake wherever adequate substrate is available.

Size frequency data reported here is suggestive of high Diporeia production rates in Lake Superior (i.e. $\mathrm{P} / \mathrm{B}>1$ ) due to the large proportions of $\mathrm{YOY}$ individuals present in almost all samples from each station. Samples collected on 4 April 2012 were the exception, however, having a relatively low proportion of YOY Diporeia. It is likely that this difference was due to sampling before females had released their eggs during that year.

The predominant macroinvertebrates in Lake Superior, as well as in other Great Lakes, have historically been found to be Diporeia, oligochaetes, sphaeriids, and chironomids (Cook and Johnson 1974; Dermott and Kerec 1997; Nalepa et al. 1998; Auer and Kahn 2004). Quantitative considerations of Great Lakes benthic communities do not typically take nematodes or ostracods into account due to the difficulty involved with efficiently sampling their populations (Alley and Mozley 1975). While these two taxa make up a large proportion of the overall number of organisms in the benthic community, nematodes, ostracods, sphaeriids, and chironomids typically account for only a small fraction of total macroinvertebrate biomass. Nalepa (1989) found that oligochaetes and Diporeia combined accounted for over $97 \%$ of benthos biomass in depths greater than $30 \mathrm{~m}$ within Lake Michigan. A thorough understanding of the composition of benthic invertebrates is important in developing accurate estimates of energy transfer within the ecosystem. This is due to the differences among benthos in assimilation efficiencies and as well as the utilization of macroinvertebrates by fish species. 


\section{PRELIMINARY GROWTH EXPERIMENTS}

A set of microcosm experiments was initiated on 9 November 2011 to quantify individual growth rates of Diporeia in a natural setting. Body lengths were to be measured at regular intervals over the course of one year, and the change in biomass would be used to calculate production for both YOY and juveniles.

\section{Diporeia collection and culture}

Samples of Diporeia were collected on 25 October 2011, placed into plastic bins with lake water from the collection sites, then transported back to the laboratory where they were stored in constant darkness at $4^{\circ} \mathrm{C}$. These animals were kept alive to be used in growth monitoring experiments. Fresh lake water was added to Diporeia cultures every two weeks.

\section{Length-weight Relationship}

Prior to the growth experiments, individual Diporeia were selected at random from samples taken on 6 October 2011 and placed onto a flat-bottomed well slide. Each amphipod $(n=59)$ was then photographed using a Nikon D50 camera that was attached to the eyepiece of a dissecting microscope using an Olympus SZ-CTV scope. Once photographed, individuals were transferred to a vial filled with water and labeled with the photograph number. Once all were photographed, each individual was weighed, wet, using a METTLER TOLEDO MX5 Automated-S Microbalance to the nearest $0.001 \mathrm{mg}$. After each wet weight was recorded, all animals were dried for 24 hours at $60^{\circ} \mathrm{C}$ (Dermott and Corning 1988; Quigley et al. 2002) and reweighed. Dry weights were also recorded to the nearest $0.001 \mathrm{mg}$. 
Total body length, defined as the distance from the tip of the rostrum to the tip of the telson following the line of the gut (Quigley and Lang 1989; Chapelle and Peck 2004), was estimated for each animal using Sigma Scan Pro-4 (version 4.01). Dry weight measurements were matched to the corresponding body length and a lengthweight relationship was determined using a non-linear regression model with the statistical software R (R Development Core Team 2011). An Excel plot of these results is shown in Figure 1.8

\section{Growth Chambers}

Sections of clear PVC pipe (255 mm in height, $145 \mathrm{~mm}$ in diameter) with two lateral openings $(20 \times 15 \mathrm{~cm})$ were covered with $210-\mu \mathrm{m}$ mesh netting to allow water to flow through. This pipe was fitted into grooves that were carved in a removable bottom plate, and secured using elastic straps. The diffusion rate and dissolved oxygen (DO) level of the water in these tubes was monitored. Petri dishes were filled with filtered lake sediment and placed at the bottom of growth chambers. The containment apparatuses were placed into a "Frigid Unit" tank filled with lake water, and the sediments were allowed to settle overnight. Water in the tank was kept between $3-5^{\circ} \mathrm{C}$ and temperature was monitored daily with the temperature control system of the chilled unit and with two thermometers that were calibrated in a $0^{\circ} \mathrm{C}$ ice bath.

\section{Sediment preparation and Diporeia handling}

Plastic bins containing unwashed PONAR samples were kept in the dark at $4^{\circ} \mathrm{C}$. In order to prepare sediment used for growth experiments, the overlying culture water from a bin was gently poured into a $10 \mathrm{~cm}$ piece of PVC pipe with a $210-\mu \mathrm{m}$ 
mesh net attached at the bottom end in order to filter out Diporeia. Small amounts of sediment were then removed using a spatula, and placed into the PVC pipe with mesh netting. Lake water was poured into the top end of the PVC pipe, and the sediment was gently stirred to allow all of the fine particles to fall through. Each petri dish was filled with $5 \mathrm{~mm}$ of filtered sediment.

Live Diporeia were consolidated by carefully stirring up the top layer of culture sediment from a bin, causing the amphipods to rise into the water, and then gently pouring the culture water through the $210-\mu \mathrm{m}$ mesh net. Organisms were immediately removed from the netting and transferred to a large petri dish kept on ice. Diporeia to be photographed were individually removed using a spatula and quickly and carefully placed onto a round-bottomed well slide.

\section{Experiment design and performance}

Nine growth chambers were prepared, as described above, and live Diporeia were introduced to each $(n=60)$. Six were devoted to housing YOY amphipods (360 total YOY), and three replicates for juveniles (defined as individuals between 3 and 6 $\mathrm{mm}$ ) (180 total juveniles). The density of Diporeia in this experiment was equivalent to $477 \cdot \mathrm{m}^{2}$. Given that the individuals in this study were YOY, and that all other benthos had been removed, it was assumed that food availability would not be limiting. During the duration of the experiment, we would monitor changes in growth by removing animals bimonthly, taking photos of each individual for determining body length, and immediately returning the animals to the tank with fresh sediment. 
After the first two months we observed a survival rate of approximately $75 \%$. All animals were photographed, and the remaining live Diporeia were returned to the growth chambers. During the second bimonthly data collection, less than $5 \%$ of the original 540 animals were still alive. At this point, the experiment was terminated. We presume the cause of the high Diporeia mortality rate observed in this experiment was related to the water movement produced by the temperature control system. This unit continuously stirred the water to maintain a constant dissolved oxygen content in the microcosms. However, the currents produced forced Diporeia that had come out of the sediment up to the water surface, where they became trapped by air bubbles under their carapace and by the surface tension, causing them to be unable to return to the bottom of the chamber.

Through these experiments, we developed a length-weight relationship for Diporeia, gained knowledge of how to properly maintain Diporeia in the lab over an extended period of time and how to accurately determine body length through digital analysis. Additionally, we became more familiar with the small scale measurements needed to determine true Diporeia growth rates. 
a)

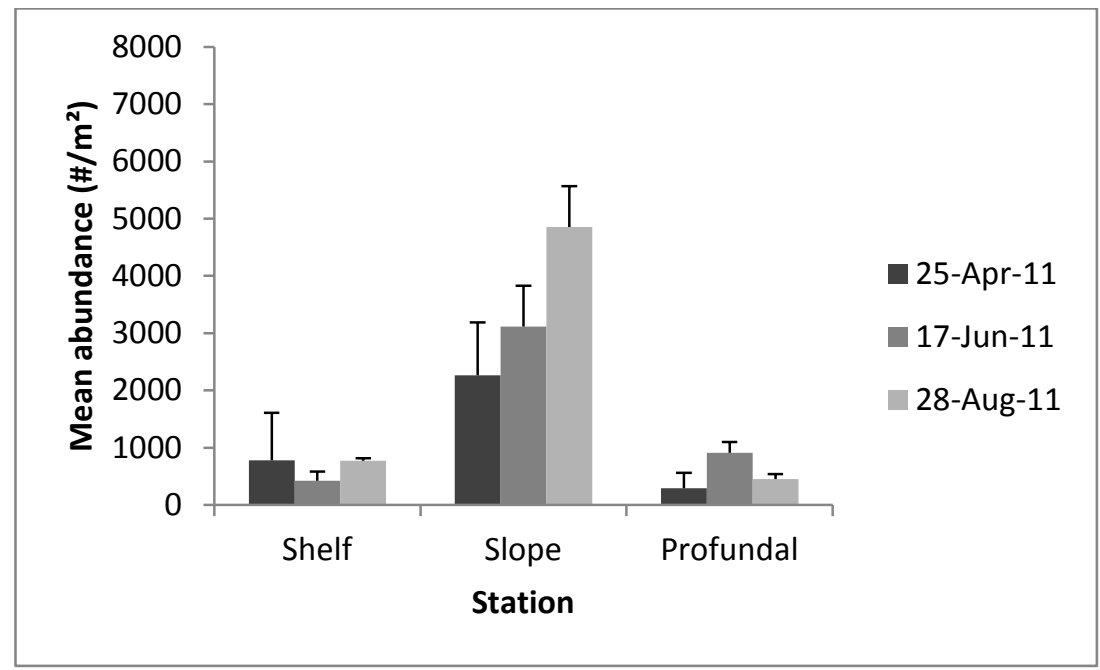

b)

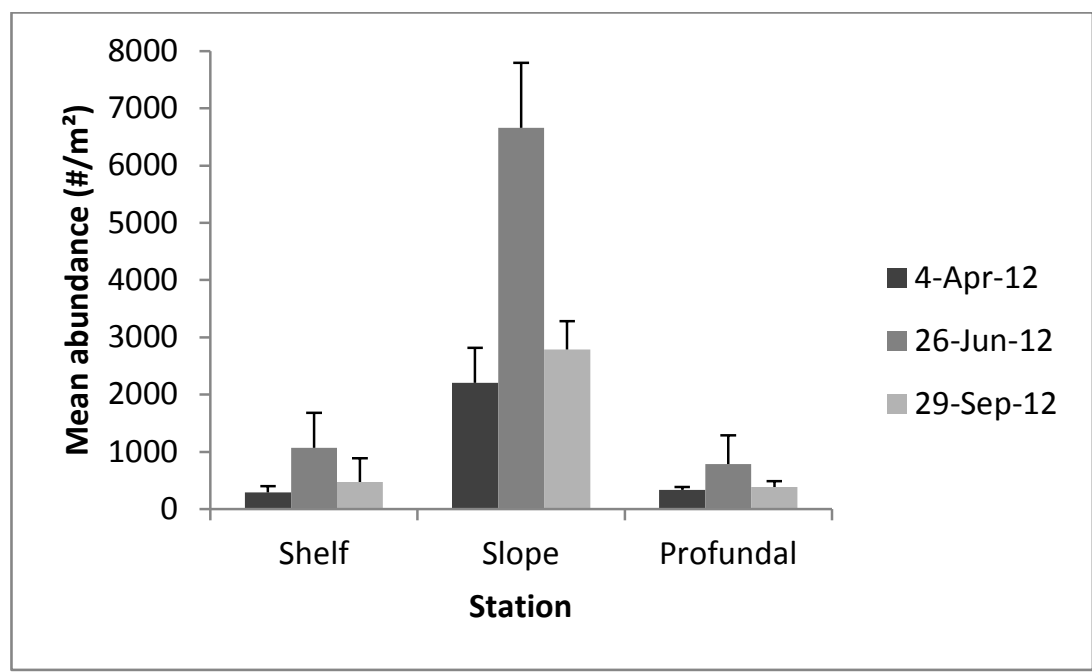

Figure 1.1 Mean abundances ( \pm SE) of Diporeia on the shelf, slope, and profundal regions of Lake Superior during spring, summer and fall of a) 2011 and b) 2012. 


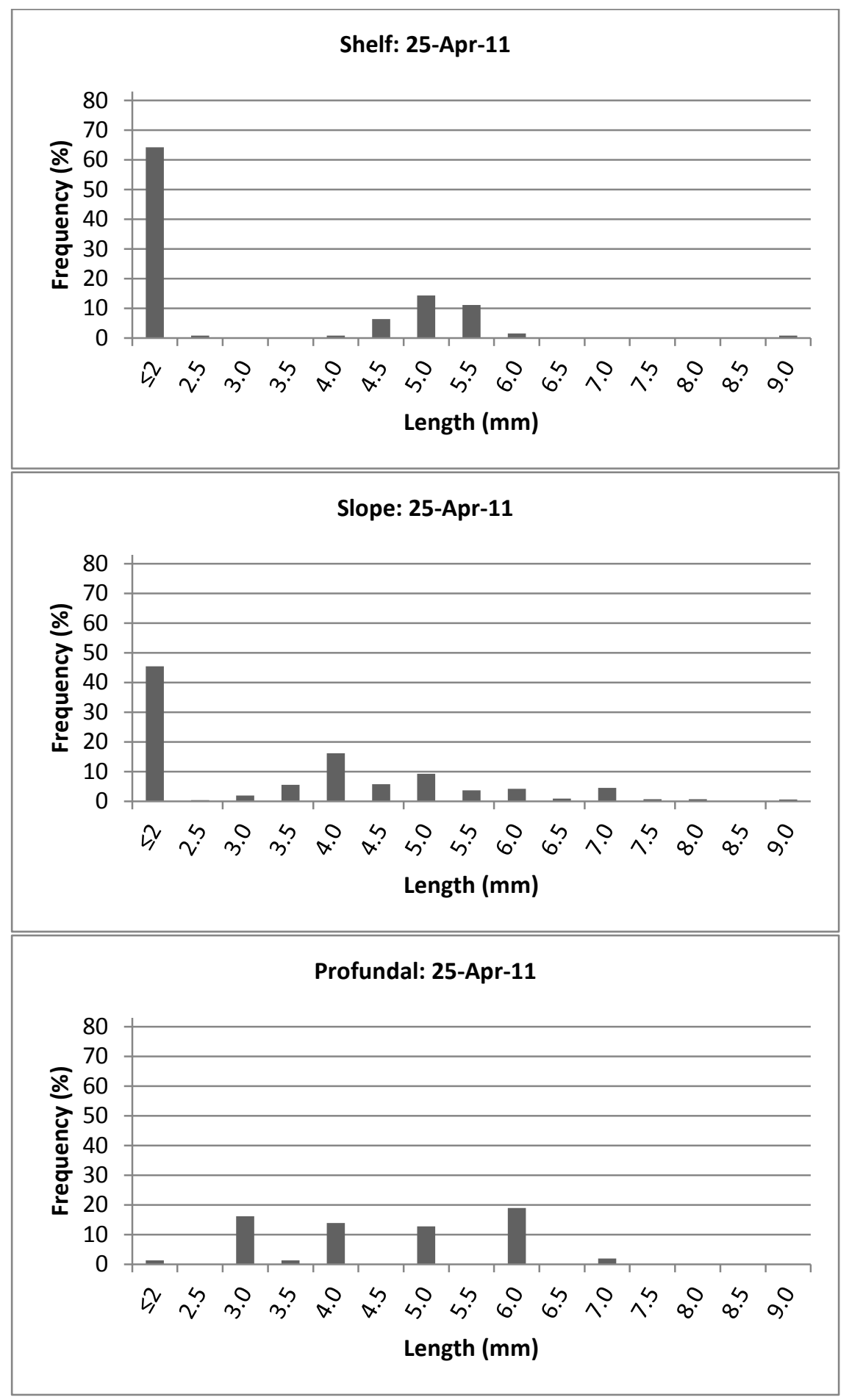

Figure 1.2 Diporeia length-frequencies for the shelf, slope, and profundal regions of Lake Superior during spring 2011. 


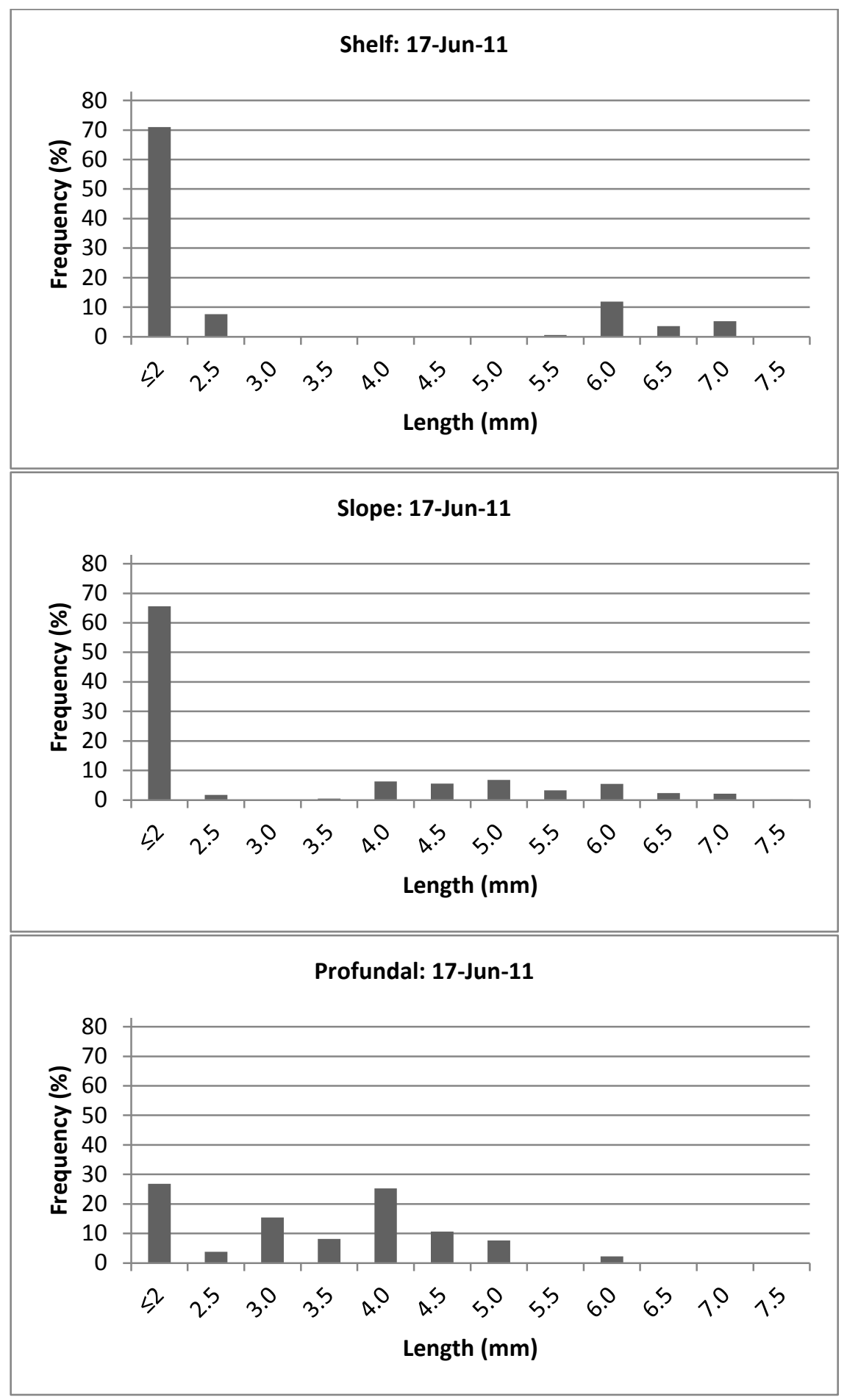

Figure 1.3 Diporeia length-frequencies for the shelf, slope, and profundal regions of Lake Superior during summer 2011. 


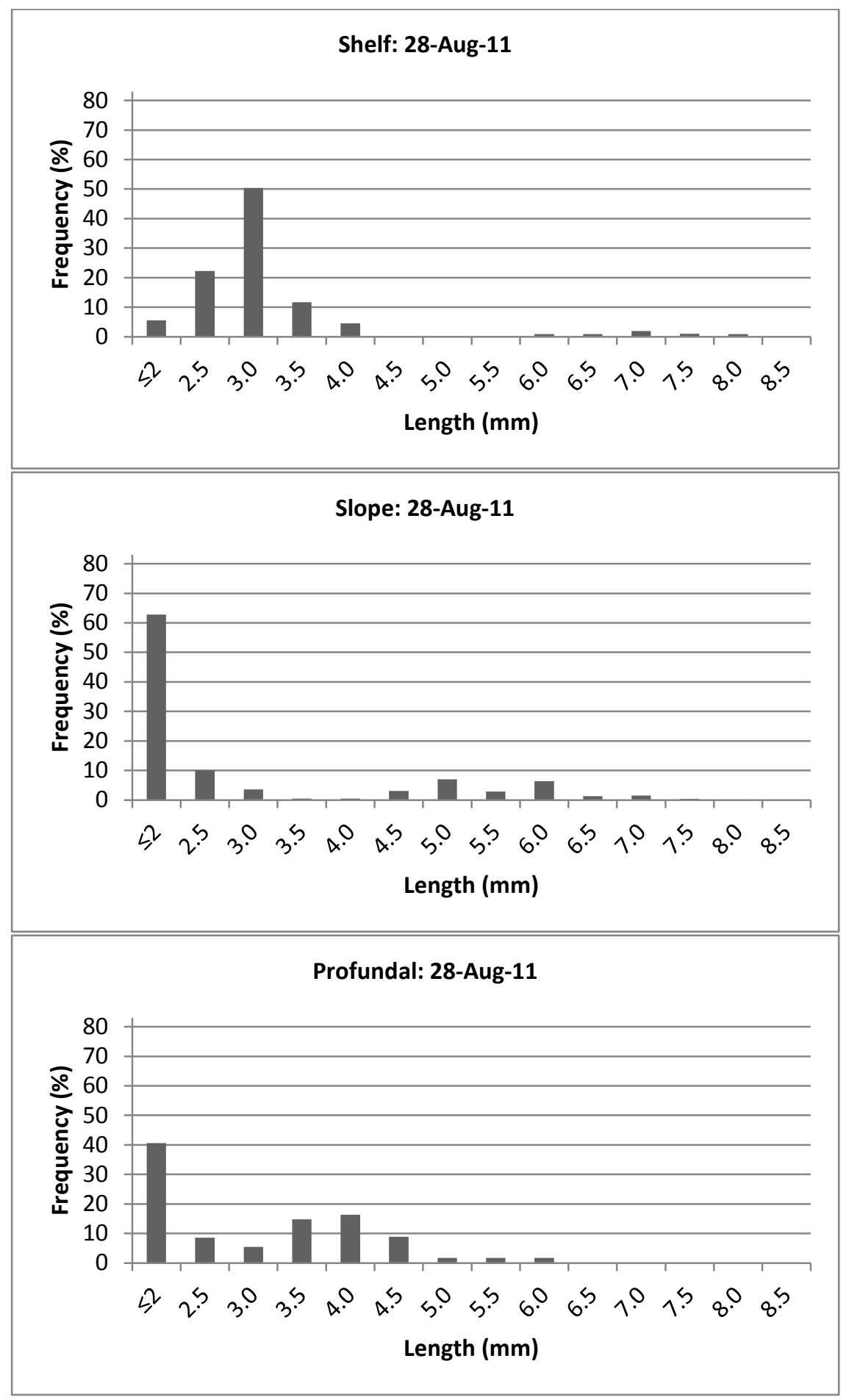

Figure 1.4 Diporeia length-frequencies for the shelf, slope, and profundal regions of Lake Superior during fall 2011. 


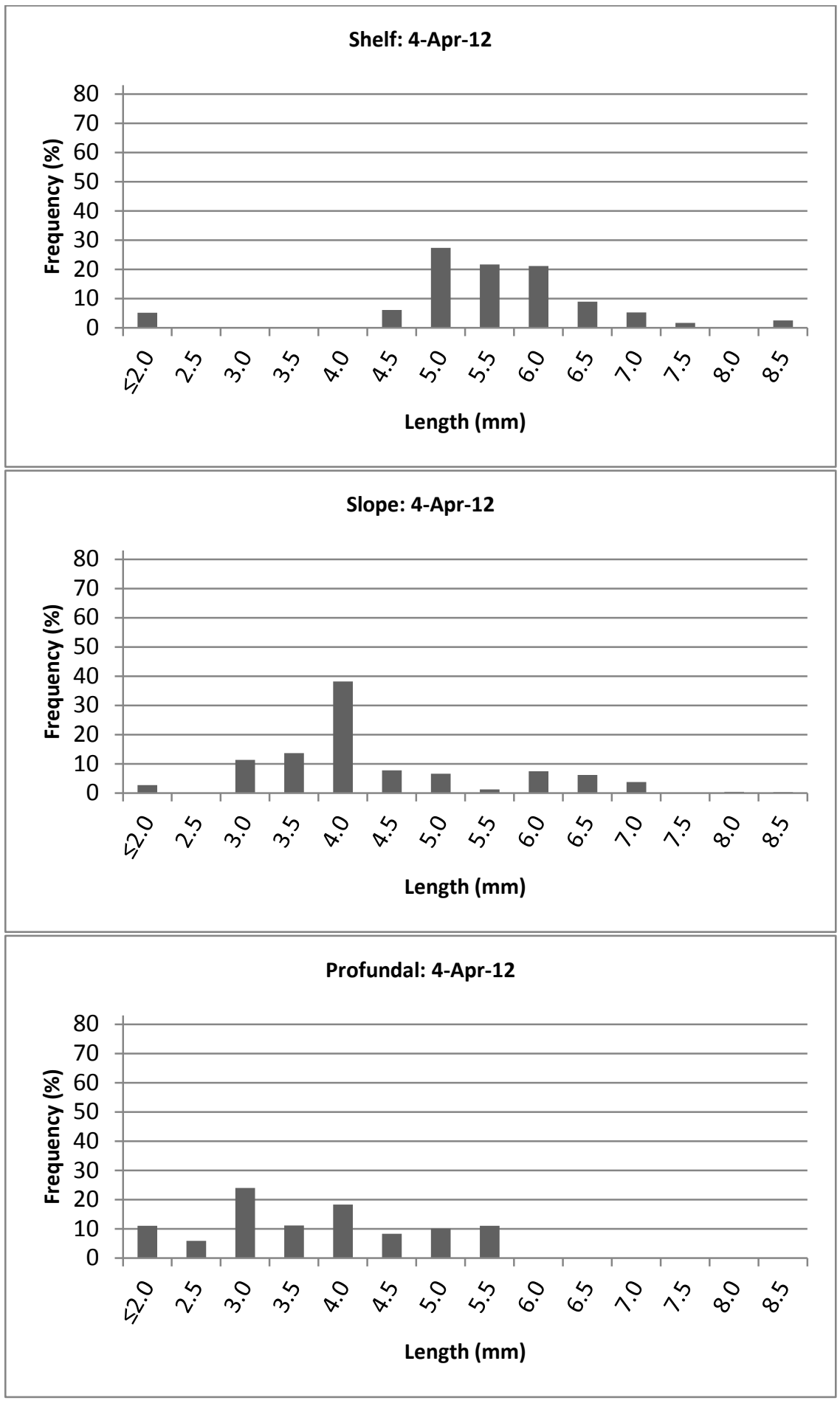

Figure 1.5 Diporeia length-frequencies for the shelf, slope, and profundal regions of Lake Superior during spring 2012. 


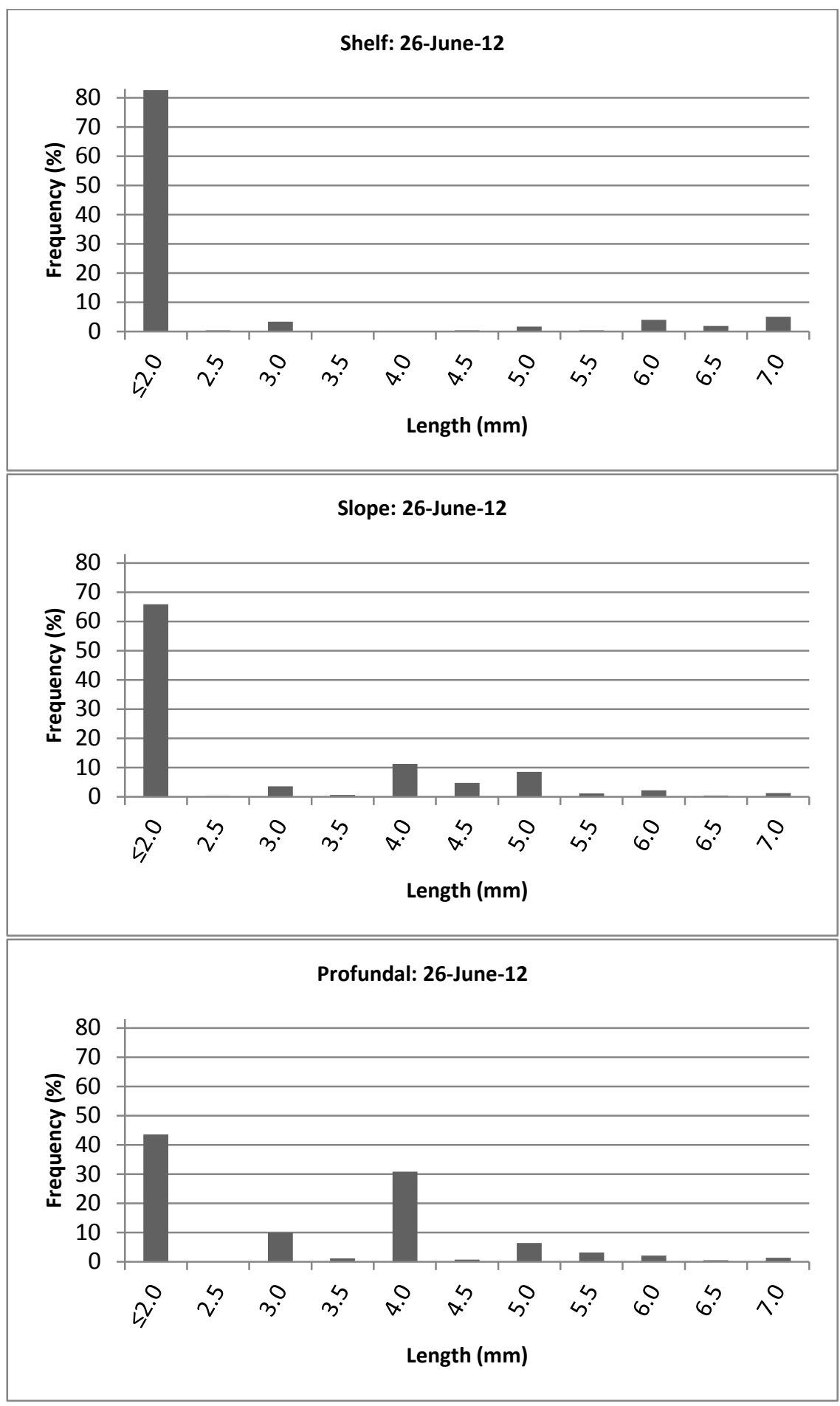

Figure 1.6 Diporeia length-frequencies for the shelf, slope, and profundal regions of Lake Superior during summer 2012. 


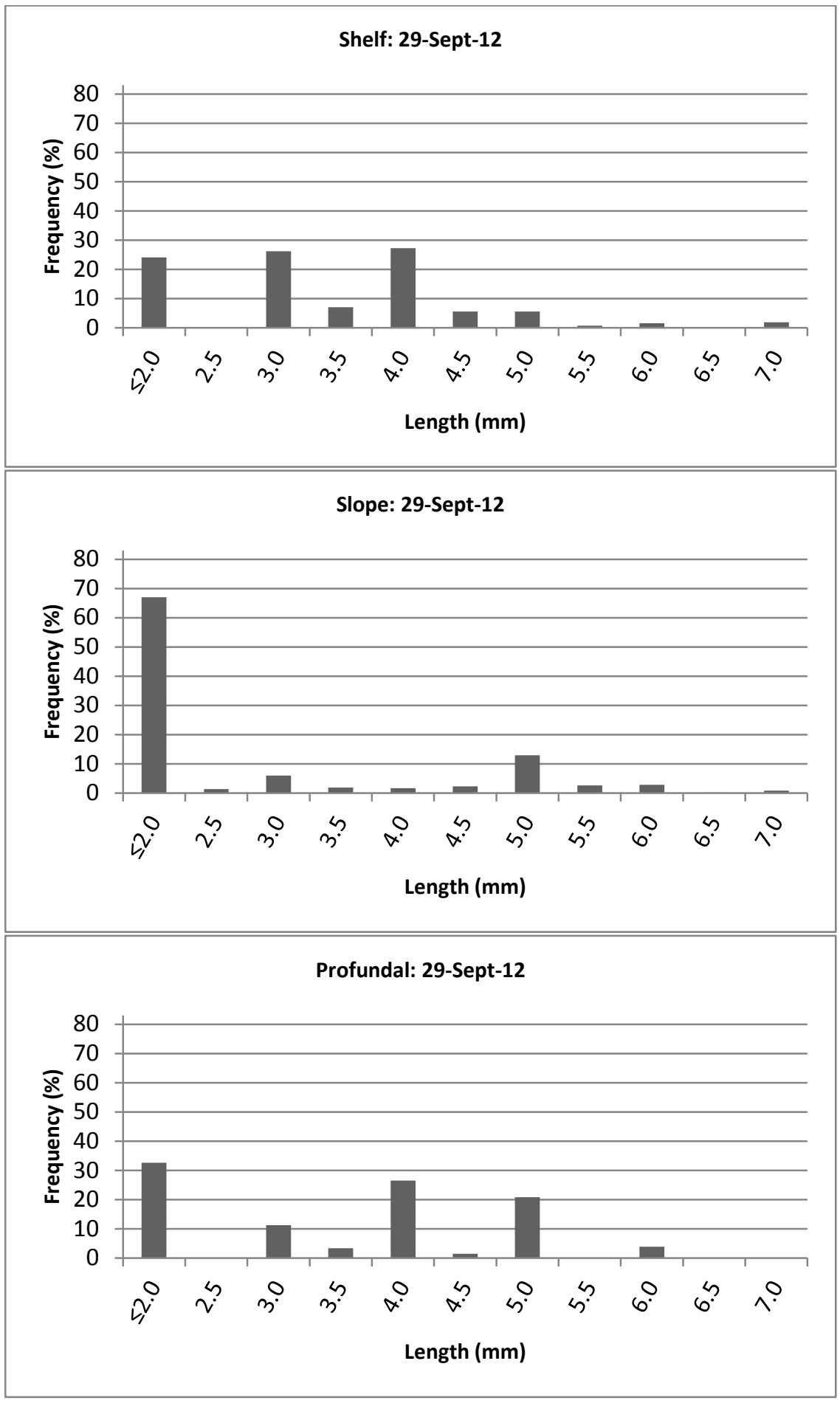

Figure 1.7 Diporeia length-frequencies for the shelf, slope, and profundal regions of Lake Superior during fall 2012. 


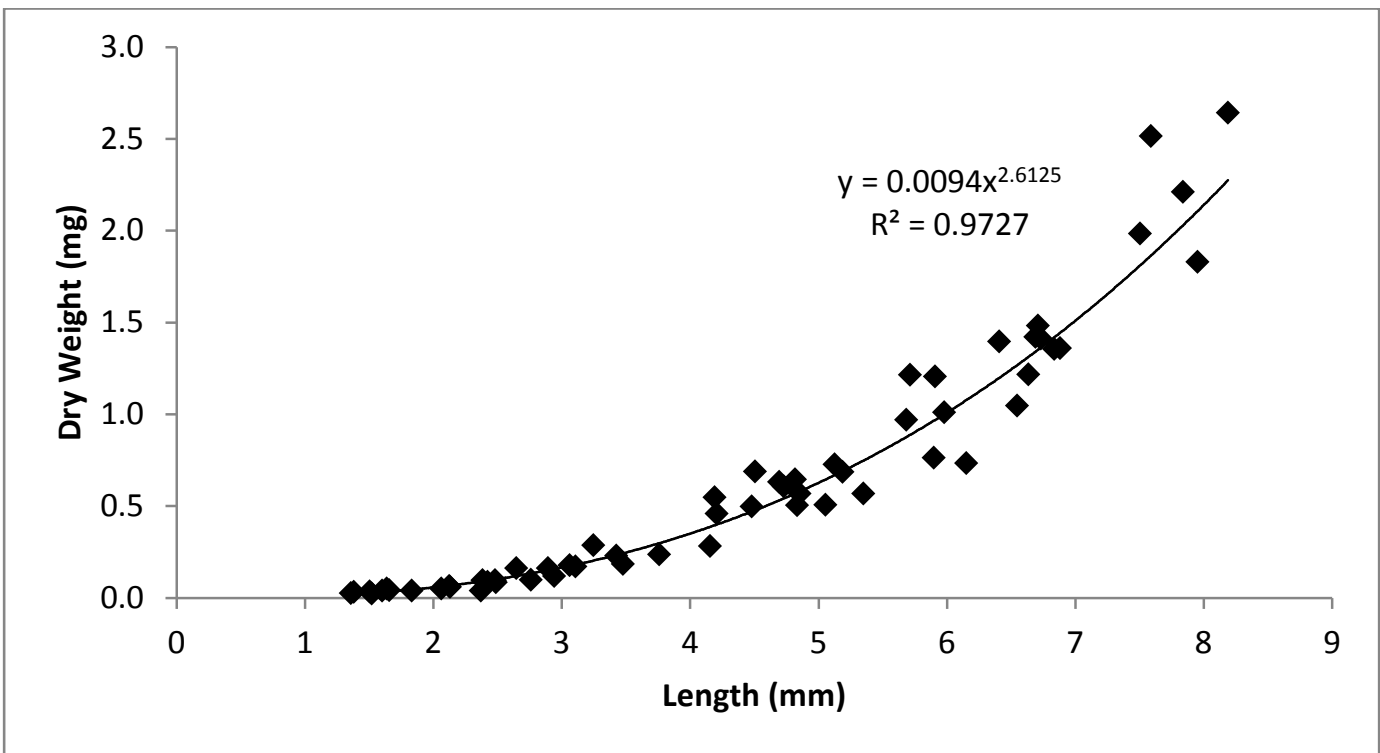

Figure 1.8 A length-weight relationship for Diporeia taken from Lake Superior on 5 October $2011(n=59)$. 
Table 1.1 Mean abundance and biomass of the four most prominent benthic invertebrates during 2011 and 2012. Values represent the mean ( \pm SE) of 53 PONAR grabs collected from the shelf, slope, and profundal regions along the western edge of the Keweenaw Peninsula in Lake Superior.

\begin{tabular}{lccc}
\hline Taxa & $\begin{array}{c}\text { Mean abundance } \\
\left(\text { individuals } \cdot \mathbf{m}^{-2}\right)\end{array}$ & $\begin{array}{c}\text { Mean biomass } \\
\left(\mathbf{g} \cdot \mathbf{m}^{-2} \text { ) }\right.\end{array}$ & $\begin{array}{c}\text { \% of total biomass } \\
\mathbf{2 0 1 1 ~ \& ~ 2 0 1 2}\end{array}$ \\
\hline Chironomidae & $194( \pm 84)$ & 0.02 & $1.15 \%$ \\
Diporeia & $1607( \pm 441)$ & 1.10 & $79.63 \%$ \\
Oligochaeta & $517( \pm 209)$ & 0.21 & $15.06 \%$ \\
Sphaeriidae & $347( \pm 148)$ & 0.06 & $4.16 \%$ \\
\hline
\end{tabular}


Table 1.2 Mean abundances (individuals $\cdot \mathrm{m}^{-2}$ ) of benthos in the shelf, slope, and profundal regions of Lake Superior during 2011.

\begin{tabular}{lcccccc}
\hline \multicolumn{1}{c}{ 23-Apr-11 } & \multicolumn{2}{c}{ Shelf } & \multicolumn{2}{c}{ Slope } & \multicolumn{2}{c}{ Profundal } \\
\hline \multicolumn{1}{c}{ Taxa } & Mean & $\mathbf{\pm S E}$ & Mean & $\mathbf{\pm S E}$ & Mean & \pm SE \\
Chironomidae & 239 & 130 & 435 & 38 & 7 & 7 \\
Diporeia & 783 & 587 & 2268 & 533 & 297 & 155 \\
Gastropod & 0 & 0 & 80 & 80 & 0 & 0 \\
Nematoda & 0 & 0 & 0 & 0 & 0 & 0 \\
Oligochaeta & 0 & 0 & 7 & 7 & 43 & 25 \\
Ostracod & 250 & 76 & 1413 & 120 & 696 & 349 \\
Sphaeriidae & 43 & 22 & 826 & 190 & 623 & 268 \\
\hline
\end{tabular}

\begin{tabular}{lcccccc}
\hline \multicolumn{1}{c}{ 17-Jun-11 } & \multicolumn{2}{c}{ Shelf } & \multicolumn{2}{c}{ Slope } & \multicolumn{2}{c}{ Profundal } \\
\hline \multicolumn{1}{c}{ Taxa } & Mean & $\mathbf{\pm S E}$ & Mean & $\mathbf{\pm S E}$ & Mean & $\mathbf{\pm S E}$ \\
Chironomidae & 326 & 113 & 275 & 97 & 22 & 13 \\
Diporeia & 428 & 91 & 3116 & 413 & 913 & 107 \\
Gastropod & 7 & 7 & 7 & 7 & 0 & 0 \\
Nematoda & 0 & 0 & 0 & 0 & 0 & 0 \\
Oligochaeta & 7 & 7 & 0 & 0 & 51 & 19 \\
Ostracod & 225 & 84 & 1616 & 477 & 428 & 51 \\
Sphaeriidae & 29 & 7 & 1087 & 124 & 1123 & 244 \\
\hline
\end{tabular}

\begin{tabular}{|c|c|c|c|c|c|c|}
\hline \multirow{2}{*}{$\begin{array}{c}\text { 28-Aug-11 } \\
\text { Taxa }\end{array}$} & \multicolumn{2}{|c|}{ Shelf } & \multicolumn{2}{|c|}{ Slope } & \multicolumn{2}{|c|}{ Profundal } \\
\hline & Mean & $\pm S E$ & Mean & \pm SE & Mean & $\pm \mathrm{SE}$ \\
\hline Chironomidae & 101 & 36 & 493 & 26 & 7 & 7 \\
\hline Diporeia & 775 & 26 & 4855 & 409 & 457 & 50 \\
\hline Gastropod & 0 & 0 & 0 & 0 & 0 & 0 \\
\hline Nematoda & 0 & 0 & 72 & 72 & 297 & 171 \\
\hline Oligochaeta & 0 & 0 & 7 & 7 & 29 & 29 \\
\hline Ostracod & 72 & 52 & 2471 & 583 & 326 & 45 \\
\hline Sphaeriidae & 43 & 43 & 1188 & 84 & 442 & 237 \\
\hline
\end{tabular}


Table 1.3 Mean abundances (individuals $\cdot \mathrm{m}^{-2}$ ) of benthos in the shelf, slope, and profundal regions of Lake Superior during 2012.

\begin{tabular}{lcccccc}
\hline \multicolumn{1}{c}{ 4-Apr-12 } & \multicolumn{2}{c}{ Shelf } & \multicolumn{2}{c}{ Slope } & \multicolumn{2}{c}{ Profundal } \\
\hline \multicolumn{1}{c}{ Taxa } & Mean & $\mathbf{\pm S E}$ & Mean & $\mathbf{\pm S E}$ & Mean & $\mathbf{\pm S E}$ \\
Chironomidae & 145 & 32 & 464 & 32 & 22 & 13 \\
Diporeia & 297 & 77 & 2210 & 352 & 341 & 26 \\
Gastropod & 7 & 9 & 0 & 0 & 0 & 0 \\
Nematoda & 0 & 0 & 0 & 0 & 0 & 0 \\
Oligochaeta & 0 & 0 & 0 & 0 & 130 & 130 \\
Ostracod & 72 & 9 & 1652 & 499 & 80 & 14 \\
Sphaeriidae & 7 & 9 & 935 & 317 & 152 & 88 \\
\hline
\end{tabular}

\begin{tabular}{lcccccc}
\hline \multicolumn{1}{c}{ 16-Jun-12 } & \multicolumn{2}{c}{ Shelf } & \multicolumn{2}{c}{ Slope } & \multicolumn{2}{c}{ Profundal } \\
\hline \multicolumn{1}{c}{ Taxa } & Mean & $\mathbf{\pm S E}$ & Mean & $\mathbf{\pm S E}$ & Mean & $\mathbf{\pm S E}$ \\
Chironomidae & 87 & 33 & 297 & 93 & 14 & 14 \\
Diporeia & 1072 & 353 & 6659 & 655 & 790 & 290 \\
Gastropod & 0 & 0 & 0 & 0 & 0 & 0 \\
Nematoda & 399 & 129 & 239 & 58 & 0 & 0 \\
Oligochaeta & 0 & 0 & 0 & 0 & 7 & 7 \\
Ostracod & 413 & 58 & 1746 & 480 & 36 & 19 \\
Sphaeriidae & 36 & 7 & 1261 & 214 & 94 & 40 \\
\hline
\end{tabular}

\begin{tabular}{lcccccc}
\hline \multicolumn{1}{c}{ 29-Sep-12 } & \multicolumn{2}{c}{ Shelf } & \multicolumn{2}{c}{ Slope } & \multicolumn{2}{c}{ Profundal } \\
\hline \multicolumn{1}{c}{ Taxa } & Mean & $\mathbf{\pm S E}$ & Mean & $\mathbf{\pm S E}$ & Mean & $\mathbf{\pm S E}$ \\
Chironomidae & 478 & 193 & 87 & 25 & 0 & 0 \\
Diporeia & 478 & 238 & 2790 & 285 & 391 & 58 \\
Gastropod & 0 & 0 & 0 & 0 & 0 & 0 \\
Nematoda & 101 & 40 & 152 & 13 & 65 & 33 \\
Oligochaeta & 0 & 0 & 14 & 7 & 0 & 0 \\
Ostracod & 152 & 66 & 551 & 44 & 29 & 19 \\
Sphaeriidae & 123 & 63 & 1145 & 122 & 138 & 95 \\
\hline
\end{tabular}




\section{REFERENCES}

Alley WP, Mozley SC. 1975. Seasonal Abundance and Spatial Distribution of Lake Michigan Macrobenthos, 1964-67. Available from the National Technical Information Service, Springfield VA 22161 as PB-257 708, Price codes: A06 in paper copy, A01 in microfiche. Report EPA-905/9-75-004, Special Report No. SR-54, Great Lakes Research Division, University of Michigan, Ann Arbor , 1975. 103 p, 30 fig, 12 tab, 49 ref, 1 append. FWPCA-WP-00311 and NSF GA-1337.

Auer MT, Auer NA, Urban NR, Auer T. 2013. Distribution of the Amphipod Diporeia in Lake Superior: The Ring of Fire. Journal of Great Lakes Research(0).

Auer NA, Kahn JE. 2004. Abundance and Distribution of Benthic Invertebrates, with Emphasis on Diporeia, along the Keweenaw Peninsula, Lake Superior. Journal of Great Lakes Research 30(Supplement 1):340-359.

Auer NA, Cannon BA, Auer MT. 2009. Life History, Distribution, and Production of Diporeia Near the Keweenaw Peninsula Lake Superior. Journal of Great Lakes Research 35(4):579-590.

Barbiero RP, Schmude K, Lesht BM, Riseng CM, Warren GJ, Tuchman ML. 2011. Trends in Diporeia populations across the Laurentian Great Lakes, 1997-2009. Journal of Great Lakes Research 37(1):9-17.

Bousfield EL. 1989. Revised morphological relationships within the amphipod genera Pontoporeia and Gammaracanthus and the "glacial relict" significance of their postglacial distributions. Canadian Journal of Fisheries and Aquatic Sciences 46(10):1714-1725.

Chapelle G, Peck LS. 2004. Amphipod crustacean size spectra: new insights in the relationship between size and oxygen. Oikos 106(1):167-175.

Cook DG, Johnson MG. 1974. Benthic Macroinvertebrates of the St. Lawrence Great Lakes. Journal of the Fisheries Research Board of Canada 31(5):763-782.

Cook DG. 1975. A Preliminary Report on the Benthic Macroinvertebrates of Lake Superior. Canada Fisheries and Marine Service Technical Report No. 572 1975. 52 p, 11 fig., 2 tab., 26 ref., 2 append.

Dermott R, Corning K. 1988. Seasonal ingestion rates of Pontoporeia hoyi (Amphipoda) in Lake Ontario. Canadian Journal of Fisheries and Aquatic Sciences 45(11):1886-1895.

Dermott R, Kerec D. 1997. Changes to the deepwater benthos of eastern Lake Erie since the invasion of Dreissena: 1979-1993. Canadian Journal of Fisheries and Aquatic Sciences 54(4):922-930.

Dermott R. 2001. Sudden Disappearance of the Amphipod< $i>$ Diporeia</i> from Eastern Lake Ontario, 1993-1995. Journal of Great Lakes Research 27(4):423.

Dermott R, Munawar M, Bonnell R, Carou S, Niblock H, Nalepa TF, Messick G. 2005. Preliminary Investigations for Causes of the Disappearance of Diporeia spp. from Lake Ontario. Great Lakes Fishery Commission.

Fore LS, Karr JR, Conquest LL. 1994. Statistical properties of an index of biological integrity used to evaluate water resources. Canadian Journal of Fisheries and Aquatic Sciences 51(5):1017-1087. 
Galloway JN, Thornton JD, Norton SA, Volchok HL, McLean RA. 1982. Trace metals in atmospheric deposition: a review and assessment. Atmospheric Environment (1967) 16(7):1677-1700.

Gardner WS, Nalepa TF, Frez WA, Cichocki EA, Landrum PF. 1985. Seasonal patterns in lipid content of Lake Michigan macroinvertebrates. Canadian Journal of Fisheries and Aquatic Sciences 42(11):1827-1832.

Golley FB. 1993. A history of the ecosystem concept in ecology: more than the sum of the parts. Yale University Press.

Gorman OT, Evrard LM, Cholwek GA, Yule DL, Vinson MR, Station LSB. 2012. Status and Trends of the Nearshore Fish Community of Lake Superior, 2011. Great Lakes Fishery Commission, Lake Superior Committee Meeting. Windsor, Ontario: US Geological Survey, Great Lakes Science Center.

Grigorovich IA. 2003. Lake Superior: an invasion coldspot? Hydrobiologia 499(1-3):191.

Kitchell JF, Stewart DJ, Weininger D. 1977. Applications of a bioenergetics model to yellow perch (Perca flavescens) and walleye (Stizostedion vitreum vitreum). J. Fish. Res. Board Can., 34(10), 1922-1935, 1977(0015-296X, 0015-296X).

Kitchell JF, Cox SP, Harvey CJ, Johnson TB, Mason DM, Schoen KK, Aydin K, Bronte C, Ebener $M$, Hansen $M$ et al. . 2000. Sustainability of the Lake Superior Fish Community: Interactions in a Food Web Context. Ecosystems 3(6):545-560.

Kraft KJ. 1979. Pontoporeia Distribution Along the Keweenaw Shore of Lake Superior Affected by Copper Tailings). Journal of Great Lakes Research Vol. 5, p 28-35, 1979. 5 fig, 3 tab, 27 ref.

Landrum PF, Nalepa TF. 1998. A Review of the Factors Affecting the Ecotoxicology of Diporeia spp. Journal of Great Lakes Research 24(4):889-904.

Landrum PF, Gossiaux DC, Nalepa TF, Fanslow DL. 2000. Evaluation of Lake Michigan Sediment For Causes of the Disappearance of Diporeia spp. in Southern Lake Michigan. Journal of Great Lakes Research 26(4):402-407.

Lindeman RL. 1942. The trophic-dynamic aspect of ecology. Ecology 23(4):399.

Lozano SJ, Scharold JV, Nalepa TF. 2001. Recent declines in benthic macroinvertebrate densities in Lake Ontario. Canadian Journal of Fisheries and Aquatic Sciences 58(3):518-529.

Lozano SJ, Gedeon ML, Landrum PF. 2003. The Effects of Temperature and Organism Size on the Feeding Rate and Modeled Chemical Accumulation in Diporeia spp. for Lake Michigan Sediments. Journal of Great Lakes Research 29(1):79-88.

Mills EL. 1994. Exotic species and the integrity of the Great Lakes. BioScience 44(10):666.

Nalepa TF, Robertson A. 1981. Screen Mesh Size Affects Estimates of Macro- and Meiobenthos Abundance and Biomass in the Great Lakes. Canadian Journal of Fisheries and Aquatic Sciences 38(9):1027-1034.

Nalepa TF. 1989. Estimates of macroinvertebrate biomass in Lake Michigan. Journal of Great Lakes Research 15(3):437.

Nalepa TF, Hartson DJ, Fanslow DL, Lang GA, Lozano SJ. 1998. Declines in benthic macroinvertebrate populations in southern Lake Michigan, 1980-1993. Canadian Journal of Fisheries and Aquatic Sciences 55(11):2402-2413. 
Nalepa TF, Mohr LC, Henderson BA, Madenjian CP, Schneeberger PJ. Lake Whitefish and Diporeia spp. in the Great Lakes: An Overview. In: Mohr LC, Nalepa TF, editors. Great Lakes Fishery Commission; Mar 2005 2005; Ann Arbor MI: Great Lakes Fishery Commission.

Nalepa TF, Fanslow DL, Foley AJ, III, Lang GA. 2006. Continued disappearance of the benthic amphipod Diporeia spp. in Lake Michigan: is there evidence for food limitation? Canadian Journal of Fisheries and Aquatic Sciences 63(4):872-890.

Nriagu JO. 1995. Dissolved trace metals in lakes Superior, Erie, and Ontario. Environmental Science \& Technology 30(1):178.

Odum HT. 1956. Primary Production in Flowing Waters. Limnology and Oceanography 1(2):102-117.

Pilgrim EM, Scharold JV, Darling JA, Kelly JR. 2009. Genetic structure of the benthic amphipod Diporeia (Amphipoda: Pontoporeiidae) and its relationship to abundance in Lake Superior. Canadian journal of fisheries and aquatic sciences/Journal canadien des sciences halieutiques et aquatiques 66(8):1318-1327.

Quigley MA, Lang GA. 1989. Measurement of amphipod body length using a digitizer. Hydrobiologia 171(3):255-258.

Quigley MA, Landrum PF, Gardner WS, Stubblefield CR, Gordon WM. 2002. Respiration, Nitrogen Excretion, and O:N Ratios of the Great Lakes Amphipod 'Diporeia' Sp.

R Development Core Team. 2011. R: A Language and Environment for Statistical Computing. Vienna, Austria: R Foundation for Statistical Computing.

Rasmussen JB, Kalff J. 1987. Empirical Models for Zoobenthic Biomass in Lakes. Canadian Journal of Fisheries and Aquatic Sciences CJFSDX Vol. 44, No. 5, p 990-1001, May 1987. 3 fig, 5 tab, 132 ref.

Rennie MD, Sprules WG, Johnson TB. 2009. Factors affecting the growth and condition of lake whitefish (Coregonus clupeaformis). Canadian journal of fisheries and aquatic sciences/Journal canadien des sciences halieutiques et aquatiques 66(12):20962108.

Reynoldson TB. 1993. The development of ecosystem objectives for the Laurentian Great Lakes. Journal of Aquatic Ecosystem Health 2(2):81-85.

Rice JA, Cochran PA. 1984. Independent evaluation of a bioenergetics model for largemouth bass. Ecology 65(3):732-739.

Scharold JV, Lozano SJ, Corry TD. 2004. Status of the Amphipod Diporeia spp. in Lake Superior, 1994-2000. Journal of Great Lakes Research 30:360-368.

Strachan WMJ, Eisenreich SJ. 1988. Mass balancing of toxic chemicals in the Great Lakes: The role of atmospheric deposition. International Joint Commission Windsor, Ontario, Canada.

Strayer D, Likens GE. 1986. An energy budget for the zoobenthos of Mirror Lake, New Hampshire. Ecology 67(2):303-313.

Urban NR, Auer MT, Green SA, Lu X, Apul DS, Powell KD, Bub L. 2005. Carbon cycling in Lake Superior. Journal of Geophysical Research. C. Oceans 110(C6).

Vanderploeg HA, Nalepa TF, Jude DJ, Mills EL, et al. 2002. Dispersal and emerging ecological impacts of Ponto-Caspian species in the Laurentian Great Lakes. Canadian Journal of Fisheries and Aquatic Sciences 59(7):1209-1228. 
Watkins JM. 2007. Evidence for remote effects of dreissenid mussels on the amphipod Diporeia: Analysis of Lake Ontario benthic surveys, 1972-2003. Journal of Great Lakes Research 33(3):642.

Wells L. 1980. Food of alewives, yellow perch, spottail shiners, trout-perch, and slimy and fourhorn sculpins in southeastern Lake Michigan. US Department of the Interior, Fish and Wildlife Service. 



\title{
CHAPTER 2. Measurement of Lake Superior Diporeia Respiration Using Microelectrodes
}

\begin{abstract}
The freshwater amphipod Diporeia is a dominant macroinvertebrate species in Lake Superior's benthic community and an important prey item for many fish. A capacity to predict growth and production rates of Diporeia using a bioenergetics model requires information on physiological processes of the species. The objective of this study is to quantify oxygen consumption of Lake Superior Diporeia and to determine if respiration rate changes by size class. Diporeia were collected from Lake Superior and kept in natural sediment maintained at $4^{\circ} \mathrm{C}$. Dissolved oxygen levels for groups of Diporeia immatures, juveniles, and adults in $20 \mathrm{~mL}$ microcosms were measured using a polarographic microelectrode. Mass-specific respiration rates for Lake Superior Diporeia ranged from 32.0 to $44.7 \mathrm{mgO}_{2} \cdot \mathrm{gDW}^{-1} \cdot \mathrm{d}^{-1}$. A significant relationship between body length and mass-specific respiration rate $(p>0.1)$ was not found. The estimate of Diporeia respiration presented here is significantly higher $(p<0.05)$ than previous findings from populations in Lake Michigan and Lake Ontario. This study provides new data on respiration rates of Diporeia in Lake Superior and compares findings to studies for other Great Lakes.
\end{abstract}

The material contained in this chapter will be submitted to the Journal of Great Lakes Research. 


\section{INTRODUCTION}

The glacial relict amphipod Diporeia has historically been a mainstay of the benthic communities in all the Laurentian Great Lakes (Stimpson 1870; Cook and Johnson 1974; Winnell and White 1984). This amphipod is a major component in the diets of numerous commercial and sport fish species (Scharold et al. 2004; Nalepa et al. 2006; Rennie et al. 2009). The extensive influence that Diporeia has on aquatic food webs (Guiguer and Barton 2002), in conjunction with this amphipod being an effective energy source for other organisms due to its high lipid content (Gardner et al. 1985; Kainz et al. 2010), indicate that this species is a key link between primary production and population dynamics of higher trophic level consumers.

Production of Diporeia in Lake Superior has been of recent concern due to its population declines in Lakes Erie, Huron, Michigan, and Ontario (Nalepa et al. 1998; Lozano et al. 2001; Lozano et al. 2003; Nalepa et al. 2006; Barbiero et al. 2011). It has been suggested that the occurrence of these declines is correlated with the introduction of non-native species, with attention concentrating on zebra and quagga mussels (Dreissena polymorpha and D. bugensis) (Landrum et al. 2000; Vanderploeg et al. 2002; Nalepa et al. 2006). Diporeia populations have yet to deviate from historical levels in Lake Superior (Cook and Johnson 1974; Kraft 1979; Auer and Kahn 2004; Barbiero et al. 2011; Auer et al. 2013), which is the only Great Lake that has not been subjected to widespread invasion by mussels. Understanding the causes of subtle changes in Diporeia physiology (e.g. respiration rate) could have a significant utility in understanding their population dynamics. For example, reduced dissolved oxygen (DO) conditions are known to have detrimental effects on 
amphipod fitness (Johansson 1997). Chapelle and Peck (2004) found that both the maximum and minimum sizes of various species of amphipods increase with increasing oxygen availability.

Additionally, oxygen uptake has been shown to be closely linked with the uptake of heavy metals and organic contaminants in Diporeia (Landrum and Stubblefield 1991). The exposure of Diporeia populations to toxicants can increase amphipod mortality rates (Landrum and Nalepa 1998) and lead to a high bioaccumulation potential through transfer to benthivorous fish species (Thomann et al. 1992). Consequently, examination of Diporeia respiratory demand will allow us to further our understanding of factors that drive population abundances of this species.

Few studies that focus on ecological monitoring of lake systems include the explicit analysis of benthic invertebrate respiration that is necessary for predicting population growth rates using bioenergetic calculations (i.e. consumption = respiration + excretion + production). This lack of data is often due to the methodological challenges associated with non-invasively measuring physiological functions (Mills 2007), yet several techniques have been developed. Studies focusing on Diporeia respiration have typically used the Winkler titration method to monitor DO content in water (Johannsson et al. 1985; Quigley et al. 2002). While this is the most widely used method for measuring DO concentrations in wet chemistry (Sahoo et al. 2010), it cannot be used to continuously monitor respiration throughout the duration of an experiment. Alternatively, polarographic microelectrodes have previously been used to monitor respiration of various living 
organisms (e.g. soil microbes, larval fish, aquatic invertebrates, etc.) and can track DO in water on a continuous scale with a response time less than one second. Johnson and Brinkhurst (1971) examined respiration rates of Lake Ontario Diporeia, as well as several other benthic invertebrate species, using a polarographic microelectrode. At the time of their study, however, the electrode required that water be constantly stirred to avoid oxygen consumption effects from the cathode. The probe used in their experiments (YSI model 54, YSI Inc., Yellow Springs, Ohio) had a probable error rate of approximately $4.8 \%$. Technological advances have since enabled these types of sensors to measure oxygen concentrations with a precision of about $0.1 \mu \mathrm{M}$, or $0.05 \%$, and without mixing the water that surrounds the sensor.

The objective of the present study is to both quantify oxygen consumption of Lake Superior Diporeia and to assess if respiration rate changes among size classes of these amphipods. Previous work by Landrum and Stubblefield (1991) and Quigley et al. (2002) suggested that body sizes of Diporeia are inversely related to their mass-specific respiration rate. Lake Superior Diporeia are hypothesized to have similar rates of respiration as those found in populations from Lake Michigan and Lake Ontario, and to have increased mass-specific respiration rates with decreasing body size.

\section{MATERIALS AND METHODS}

\section{Animal Collection and Maintenance}

During October 2012, samples were collected aboard the R/V Agassiz from a $70 \mathrm{~m}$ deep station in Lake Superior located approximately $5 \mathrm{~km}$ offshore on the 
western coast of the Keweenaw Peninsula, Michigan, USA. Sediment with live Diporeia was collected using a PONAR grab (area $=0.046 \mathrm{~m}^{2}$ ) and placed into plastic bins with lake water from the collection sites, then transported back to the laboratory where they were stored in constant darkness at $4^{\circ} \mathrm{C}$. Fresh lake water was added to Diporeia cultures every two weeks.

\section{Microelectrodes}

Diporeia respiration was estimated using an OX50 Unisense microsensor (Unisense A/S, Aarhus, Denmark) to measure oxygen partial pressure (pA) during laboratory experiments. Data acquisition was performed automatically using SensorTrace PRO 3.0.1 (Microsoft Excel format, Unisense A/S). The sensor used was a Clark-type polarographic microelectrode that allowed oxygen to diffuse through a thin silicone membrane to a polarized cathode (Oxygen Sensor Manual, Unisense A/S). This cathode reduced oxygen and the reduction current was measured and reported by the Unisense Microsensor Multimeter in millivolts (mV). Because these microsensors respond linearly to changes in oxygen levels, it was assumed that two points would be sufficient for calibrating the sensor to report the correct oxygen concentration. Calibration was performed before each experiment using both an oxygen-free solution and an oxygen-saturated solution. A zero reading was obtained by placing the sensor into an anoxic solution of $\approx 2 \mathrm{~g}$ sodium ascorbate dissolved in $100 \mathrm{ml}$ of $0.1 \mathrm{M} \mathrm{NaOH}$. Once the signal had stabilized, the $\mathrm{mV}$ output was set as $0 \mathrm{mg} \mathrm{O} \mathrm{O}_{2} \cdot \mathrm{L}^{-1}$. The sensor was then rinsed and placed into filtered lake water that had been completely aerated through vigorous bubbling. 
After the readings had once again stabilized, the signal was set as our value for fully saturated conditions. Each experiment was performed using the same electrode.

At the start of each trial, oxygen is contained within the electrolyte, resulting in extremely high initial readings (Gundersen et al. 1998). A series of control runs was required to account for this difference between observed and actual DO concentrations. Additionally, control trials revealed any background change in DO concentrations due to oxygen consumption by the electrode (Marsh and Manahan 1999). Oxygen levels were monitored in several vials containing only filtered lake water at $4^{\circ} \mathrm{C}$. The average for these control rates was subtracted from the oxygen depletion results obtained in trials with animals before any further data analysis.

\section{Oxygen Uptake Experiments}

Respiration rates of Lake Superior Diporeia were obtained from an analysis of microcosm DO concentrations in a series of experiments during OctoberDecember 2012. Diporeia were gently sieved from laboratory cultures and individuals to be used in each trial were selected based on approximate size. A total of 13 trials were conducted for three size classes: individuals with body lengths of approximately $2 \mathrm{~mm}$ were considered immatures $(n=4)$, individuals with body lengths of approximately $4 \mathrm{~mm}$ were considered juveniles $(n=5)$, and individuals with body lengths of approximately $6 \mathrm{~mm}$ were considered adults $(\mathrm{n}=4)$. The number of individuals used was typically around 10 for trials with juveniles and with adults. Additional animals were used for trials with immatures (19-22 individuals) in order to more accurately detect changes in DO concentrations. Amphipods were placed into vials filled with $20 \mathrm{~mL}$ of fully-oxygenated filtered lake water $(0.7-\mu \mathrm{m}$ GF/F filters). 
Vials were then equipped with a microelectrode and sealed with no air between the water and cap. It was assumed that the absence of sediment would not alter Diporeia respiration based on previous findings (Quigley et al. 2002). Dissolved oxygen content of the system was tracked for five hours. This duration was chosen in order to eliminate the possibility of decreased oxygen availability associated with bottle effects. Extending the time of each experiment would also result in decreasing the frequency of readings due to the software's data storage limitations. Initial $\mathrm{O}_{2}$ concentrations during each of the trials varied slightly, yet never fell below $20 \%$ of the initial concentration.

Immediately after the experiment Diporeia were individually photographed using a QImaging MicroPublisher 5.0 RTV camera (QImaging, Surrey, BC) and body lengths were determined using the image processing program Image-Pro Plus 7.0. The length of each animal was measured from the tip of the rostrum to the tip of the telson following the gut line. Animals were then grouped together, dried at $60^{\circ} \mathrm{C}$ for 24 hours, and weighed to the nearest $0.001 \mathrm{mg}$. Mass-specific respirations rates (i.e. $\mathrm{mgO}_{2} \cdot \mathrm{gDW}^{-1} \cdot \mathrm{d}^{-1}$ ) were calculated as the slope of the oxygen depletion curve divided by the total dry weight of Diporeia biomass present.

Animals were sieved from laboratory cultures, transported to a separate incubator for the experiment, and occupied the vials for 1.25 hours before $\mathrm{O}_{2}$ depletion rates were tracked. Though previous work has shown that Diporeia have elevated respiration rates after being introduced to a new environment (Quigley et al. 2002), no initial increase in respiration rate was observed in this study when monitored for 24 hours. In preliminary trials, $\mathrm{O}_{2}$ depletion rates stayed constant for 
the initial nine hours and then began to fluctuate. We speculate that this variation in depletion rates was due to bottle effects (i.e. insufficient oxygen supply).

Subsequently, experiment durations were limited to five hours. The experimental animal density in each trial (8-22 individuals per vial) was chosen based on the DO detection limits of the electrode.

\section{Statistics}

Given that this series of experiments focused on the relationship between the rate of oxygen consumption and Diporeia size, allometric effects on respiration rates were evaluated. To accomplish this, a linear regression was used to determine if mass-specific respiration rates varied significantly with body length. Analyses were conducted in the statistical software program $R$ (R Development Core Team 2011) and significance evaluated at $\alpha=0.05$.

\section{RESULTS}

Control trials consistently showed an exponential decline of observed DO within the first hour (Figure 2.1). These declines were attributed to sensor stabilization (see Methods section above) and only data collected from 1.25 hours to the end of each trial were used in statistical analyses. The sensor readings exhibited an average decline in $\mathrm{DO}$ of $0.02 \mathrm{mg} \cdot \mathrm{L}^{-1} \cdot \mathrm{h}^{-1}$ for the duration of each control trial after 1.25 hours $(n=7)$. Rates of $\mathrm{O}_{2}$ depletion in all respiration trials were calculated by subtracting 0.02 from the slope of DO content $\left(\mathrm{mg} \cdot \mathrm{L}^{-1}\right)$ vs. time (hours).

Mass-specific respiration rates for Lake Superior Diporeia ranged from 32.0 to $44.7 \mathrm{mgO}_{2} \cdot \mathrm{gDW}^{-1} \cdot \mathrm{d}^{-1}$ (Table 2.1 ). The average respiration rate among all size 
classes was $38.2 \pm 1.1(\mathrm{SE}) \mathrm{mgO}_{2} \cdot \mathrm{gDW}^{-1} \cdot \mathrm{d}^{-1}$, with a coefficient of variation of $10 \%$. Immature Diporeia had an average body length of $2.6 \pm 0.1$ (SE) and an average respiration rate of $40.1 \mathrm{mgO}_{2} \cdot \mathrm{gDW}^{-1} \cdot \mathrm{d}^{-1}$. Juveniles had an average body length of $4.68 \pm 0.2(\mathrm{SE})$ and an average respiration rate of $38.5 \mathrm{mgO}_{2} \cdot \mathrm{gDW}^{-1} \cdot \mathrm{d}^{-1}$. Adults had an average body length of $6.28 \pm 0.2$ (SE) and an average respiration rate of 35.9 $\mathrm{mgO}_{2} \cdot \mathrm{gDW}^{-1} \cdot \mathrm{d}^{-1}$.

A linear regression analysis (Figure 2.2) of average Diporeia body length from each trial did not show a significant relationship between this variable and mass-specific respiration rate $\left(R^{2}=0.10, F(1,11)=2.27, p=0.16\right)$. The data was assumed to be homoscedastic based on a Shapiro-Wilk test $(p>0.05)$ and the linear relationship observed in a $Q Q$ plot. The mean Diporeia respiration rate found in this study was found to be significantly higher than previous findings from Diporeia populations in Lake Michigan and Lake Ontario (Welch's t-test, $\mathrm{P}<0.05$ ).

\section{DISCUSSION}

In this study, higher respiration rates were observed for Lake Superior Diporeia populations than have been shown for other Great Lakes. One possible explanation could be due to diverse life history strategies developed within different lake environments. This theory of distributional diversity among amphipods in the Great Lakes was first proposed by Bousfield (1989). Although the mechanisms contributing to between lake variations are not clearly understood, some evidence has been found in recent studies. Quigley et al. (2002) found that the mean respiration rate for Lake Michigan Diporeia ranged from 13.9 to $33.9 \mathrm{mgO}_{2} \cdot \mathrm{gDW}^{-1} \cdot \mathrm{d}^{-}$ ${ }^{1}$, which was higher than the $4.0 \mathrm{mgO}_{2} \cdot \mathrm{gDW}^{-1} \cdot \mathrm{d}^{-1}$ and $18.9 \mathrm{mgO}_{2} \cdot \mathrm{gDW}^{-1} \cdot \mathrm{d}^{-1}$ 
previously reported by Johnson and Brinkhurst (1971) and by Johannsson et al. (1985), respectively, for animals from Lake Ontario. This difference was attributed to the potential existence of several Diporeia sub-species throughout the Great Lakes. Auer et al. (2009) found a substantial difference between length-weight relationships for Diporeia from Lake Superior compared to Lake Michigan and Lake Ontario Diporeia (Winnell and White 1984; Cavaletto et al. 1996). Although Auer et al. (2009) found a similar average lipid content (mean=30.8\%) among Great Lakes populations, amphipods from Lake Superior clearly exhibited different physiological characteristics by having less mass per unit length. However, the most notable support of the idea of variance among lake populations comes from the genetic analysis performed by Pilgrim et al. (2009), who determined that Lake Superior Diporeia exhibit different haplotypes than those found in any of the other Great Lakes. These results do not suggest that Lake Superior Diporeia should be classified as a separate species, but rather they have evolutionarily and perhaps physiologically diverged from populations in other Great Lakes.

A second possibility for the higher respiration rates observed in this study may be the difference in measurement techniques (Table 2.2). Determination of metabolic demands for aquatic invertebrates such as Diporeia is often a challenging process due to the small size of subjects and the potential stress involved with in vitro studies. Johnson and Brinkhurst (1971) measured Diporeia respiration rates using an oxygen microelectrode fitted with an oscillating stirrer to prevent background oxygen consumption by the cathode. In this research, the dissolved oxygen content of microcosms was tracked throughout the course of each 
experiment without generating any water movement or disturbance. Additionally, the newer model of sensor has a minute tip size which allowed for a relatively smaller microcosm $(20 \mathrm{~mL})$ to be used in the experiments, ensuring that the water being measured was representative of the area that the animals were occupying. The use of polarographic microelectrodes is thought to be a more appropriate method of determining Diporeia respiration rates than Winkler titration because they are able to detect the dissolved oxygen concentrations of small scale microcosms on a continuous scale without disturbing the sample.

In this study, a significant relationship between respiration rate and body size of Diporeia was not observed. These results suggest that Lake Superior Diporeia respiration rates may be estimated from data only on amphipod biomass. This would allow models aimed at predicting carbon turnover and biogeochemical balances associated with Lake Superior's benthic community to estimate this metabolic rate without requiring a Diporeia size-frequency coefficient. Not including life stage data in lake wide respiration estimates would be beneficial to researchers since the most parsimonious model is often the most desirable in order to maintain statistical power.

The physiological characteristics of Lake Superior Diporeia that contribute to the lack of observed size dependence in respiration are not clearly understood. Since Diporeia densities vary among different regions of the lake, a comparison of respiration rates between populations from different depths in Lake Superior may provide further insights into Diporeia bioenergetics for modeling lake-wide ecosystem function. The results presented here suggest that continuing physiological studies (i.e. investigations of consumption, excretion, and growth rates) specific to Diporeia 
in Lake Superior will aid in the capacity to predict ecosystem responses to anthropogenic influences such as pollution, the introduction of invasive species, or global climate change. 


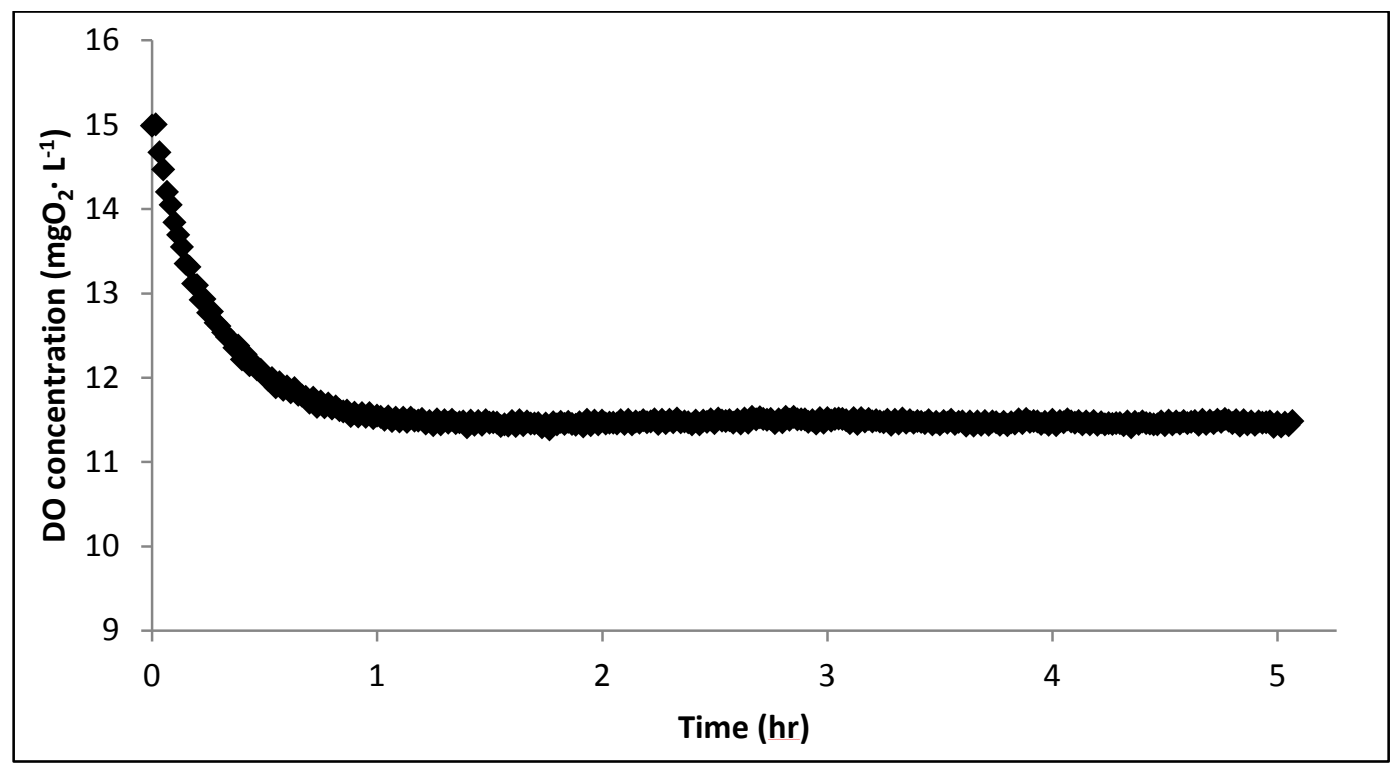

Figure 2.1 Observed dissolved oxygen (DO) concentrations over time during a control trial (i.e. no test animals in microcosm). The decrease in DO concentration during the first 1.25 hours is due to oxygen contained within the electrolyte being reduced by the cathode. 


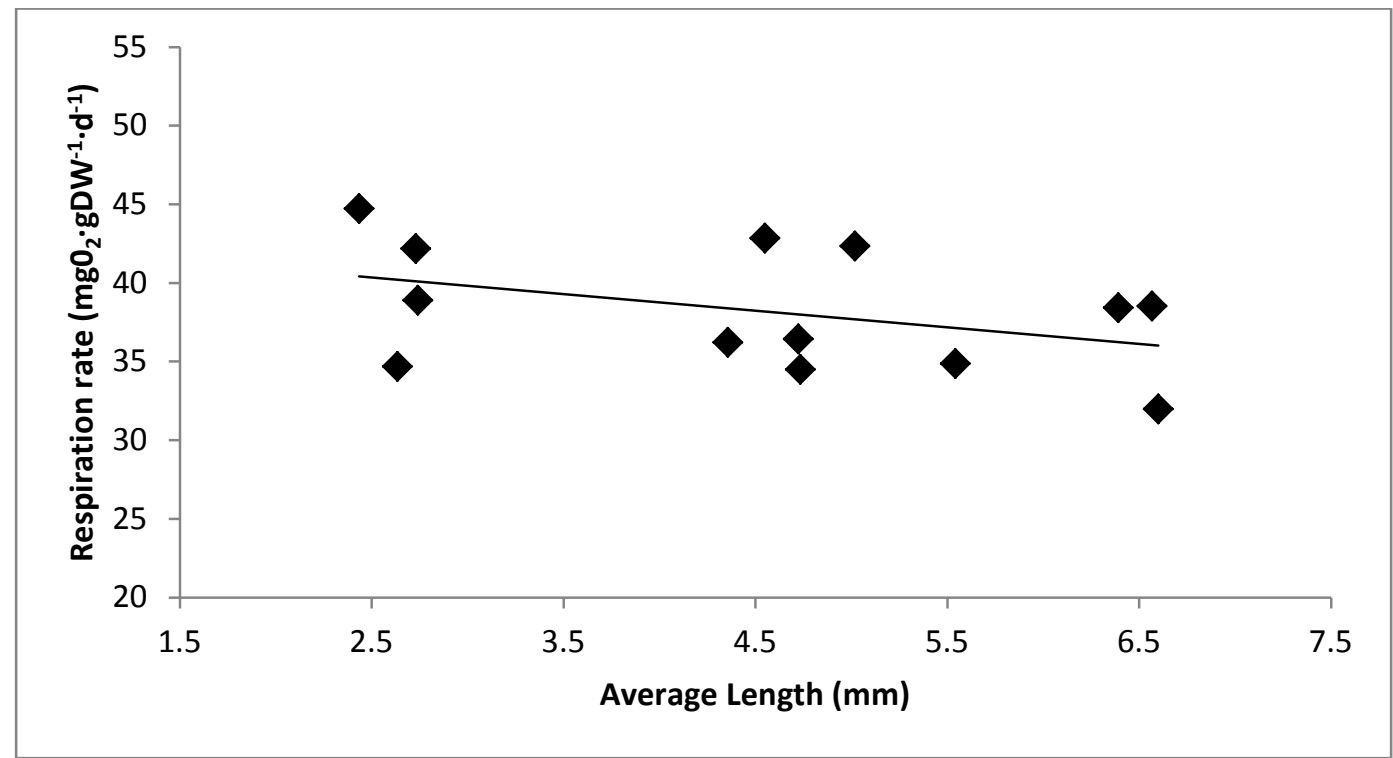

Figure 2.2 Relationship between Diporeia body length and mass-specific respiration $\left(\mathrm{mgO}_{2} \cdot \mathrm{gDW}^{-1} \cdot \mathrm{d}^{-1}\right)$. Animal size was shown to have no significant relationship with respiration rate $(p=0.16)$. 
Table 2.1 Respiration rates for three size classes (mean body length \pm mean SE) of Lake Superior Diporeia based on $\mathrm{O}_{2}$ depletion and the total dry weight of all individuals in each trial.

\begin{tabular}{|c|c|c|c|}
\hline $\begin{array}{l}\text { Size Class } \\
\text { (mm) }\end{array}$ & $\begin{array}{c}\text { Rate of } \mathrm{O}_{2} \\
\text { Depletion } \\
\left(\mathrm{mgO}_{2} \cdot \mathrm{L}^{-1} \cdot \mathrm{hr}^{-1}\right)\end{array}$ & $\begin{array}{l}\text { Dry Weight of } \\
\text { Cohort (mg) }\end{array}$ & $\begin{array}{l}\text { Respiration Rate } \\
\left(\mathrm{mgO}_{2} \cdot \mathrm{gDW}^{-1} \cdot \mathrm{d}^{-1}\right)\end{array}$ \\
\hline \multirow{4}{*}{$\begin{array}{l}\text { Immatures } \\
(2.64 \pm 0.08)\end{array}$} & 0.14 & 1.55 & 44.72 \\
\hline & 0.15 & 2.03 & 34.68 \\
\hline & 0.17 & 1.99 & 42.19 \\
\hline & 0.14 & 1.72 & 38.89 \\
\hline \multirow{5}{*}{$\begin{array}{l}\text { Juveniles } \\
(4.68 \pm 0.15)\end{array}$} & 0.39 & 4.44 & 42.34 \\
\hline & 0.38 & 4.95 & 36.44 \\
\hline & 0.37 & 4.20 & 42.85 \\
\hline & 0.38 & 5.32 & 34.49 \\
\hline & 0.33 & 4.37 & 36.22 \\
\hline \multirow{4}{*}{$\begin{array}{l}\text { Adults } \\
(6.28 \pm 0.24)\end{array}$} & 0.93 & 11.57 & 38.51 \\
\hline & 0.72 & 10.74 & 31.97 \\
\hline & 0.48 & 6.57 & 34.86 \\
\hline & 0.68 & 8.48 & 38.41 \\
\hline
\end{tabular}


Table 2.2 Comparison of literature values for the respiration rate $\left(\mathrm{mgO}_{2} \cdot \mathrm{gDW}^{-1} \cdot \mathrm{d}^{-1}\right)$ of juvenile Diporeia (mean dry weight of $1.6 \mathrm{mg}$ ).

\begin{tabular}{|c|c|c|c|}
\hline Study & $\begin{array}{c}\text { Respiration } \\
\text { Rate }\end{array}$ & $\begin{array}{c}\text { Method of } \mathbf{O}_{2} \\
\text { Measurements }\end{array}$ & Sample Site \\
\hline $\begin{array}{c}\text { Johnson and } \\
\text { Brinkhurst } \\
1971\end{array}$ & 4.0 & $\begin{array}{c}\text { Oxygen electrode } \\
\text { equipped with oscillating } \\
\text { stirrer. }\end{array}$ & Lake Ontario \\
\hline $\begin{array}{c}\text { Johannsson et } \\
\text { al. } 1985\end{array}$ & 18.9 & Winkler titration. & Lake Ontario \\
\hline $\begin{array}{c}\text { Quigley et al. } \\
2002\end{array}$ & 33.9 & Winkler titration. & Lake Michigan \\
\hline Present study & 38.2 & $\begin{array}{c}\text { Oxygen electrode with no } \\
\text { water movement or } \\
\text { disturbance. }\end{array}$ & Lake Superior \\
\hline
\end{tabular}




\section{REFERENCES}

Auer MT, Auer NA, Urban NR, Auer T. 2013. Distribution of the Amphipod Diporeia in Lake Superior: The Ring of Fire. Journal of Great Lakes Research(0).

Auer NA, Kahn JE. 2004. Abundance and Distribution of Benthic Invertebrates, with Emphasis on Diporeia, along the Keweenaw Peninsula, Lake Superior. Journal of Great Lakes Research 30(Supplement 1):340-359.

Auer NA, Cannon BA, Auer MT. 2009. Life History, Distribution, and Production of Diporeia Near the Keweenaw Peninsula Lake Superior. Journal of Great Lakes Research 35(4):579-590.

Barbiero RP, Schmude K, Lesht BM, Riseng CM, Warren GJ, Tuchman ML. 2011. Trends in Diporeia populations across the Laurentian Great Lakes, 1997-2009. Journal of Great Lakes Research 37(1):9-17.

Bousfield EL. 1989. Revised morphological relationships within the amphipod genera Pontoporeia and Gammaracanthus and the "glacial relict" significance of their postglacial distributions. Canadian Journal of Fisheries and Aquatic Sciences 46(10):1714-1725.

Cavaletto JF, Nalepa TF, Dermott R, Gardner WS, Quigley MA, Lang GA. 1996. Seasonal variation of lipid composition, weight, and length in juvenile Diporeia spp. (Amphipoda) from Lakes Michigan and Ontario. Canadian Journal of Fisheries and Aquatic Sciences 53(9):2044-2051.

Chapelle G, Peck LS. 2004. Amphipod crustacean size spectra: new insights in the relationship between size and oxygen. Oikos 106(1):167-175.

Cook DG, Johnson MG. 1974. Benthic Macroinvertebrates of the St. Lawrence Great Lakes. Journal of the Fisheries Research Board of Canada 31(5):763-782.

Gardner WS, Nalepa TF, Frez WA, Cichocki EA, Landrum PF. 1985. Seasonal patterns in lipid content of Lake Michigan macroinvertebrates. Canadian Journal of Fisheries and Aquatic Sciences 42(11):1827-1832.

Guiguer K, Barton. 2002. The Trophic Role of Diporeia (Amphipoda) in Colpoys Bay (Georgian Bay) Benthic Food Web: a Stable Isotope Approach. Journal of Great Lakes Research 28(2):228-239.

Gundersen JK, Ramsing NB, Glud RN. 1998. Predicting the Signal of O2 Microsensors from Physical Dimensions, Temperature, Salinity, and 02 Concentration. Limnology and Oceanography 43(8):1932-1937.

Johannsson OE, Dermott RM, Feldkamp R, Moore JE. 1985. Lake Ontario Long Term Biological Monitoring Program: Report for 1981 and 1982.

Johansson B. 1997. Behavioural response to gradually declining oxygen concentration by Baltic Sea macrobenthic crustaceans. Marine Biology 129(1):71.

Johnson MG, Brinkhurst RO. 1971. Production of Benthic Macroinvertebrates of Bay of Quinte and Lake Ontario. J FISH RES BOARD CAN. VOL 28, NO 11, P 1699-1714. 1971.

Kainz MJ, Johannsson OE, Arts MT. 2010. Diet effects on lipid composition, somatic growth potential, and survival of the benthic amphipod Diporeia spp. Journal of Great Lakes Research 36(2):351-356. 
Kraft KJ. 1979. Pontoporeia Distribution Along the Keweenaw Shore of Lake Superior Affected by Copper Tailings). Journal of Great Lakes Research Vol. 5, p 28-35, 1979. 5 fig, 3 tab, 27 ref.

Landrum PF, Stubblefield CR. 1991. Role of respiration in the accumulation of organic xenobiotics by the amphipod Diporeia sp. Environmental Toxicology and Chemistry 10(8):1019-1028.

Landrum PF, Nalepa TF. 1998. A Review of the Factors Affecting the Ecotoxicology of Diporeia spp. Journal of Great Lakes Research 24(4):889-904.

Landrum PF, Gossiaux DC, Nalepa TF, Fanslow DL. 2000. Evaluation of Lake Michigan Sediment For Causes of the Disappearance of Diporeia spp. in Southern Lake Michigan. Journal of Great Lakes Research 26(4):402-407.

Lozano SJ, Scharold JV, Nalepa TF. 2001. Recent declines in benthic macroinvertebrate densities in Lake Ontario. Canadian Journal of Fisheries and Aquatic Sciences 58(3):518-529.

Lozano SJ, Gedeon ML, Landrum PF. 2003. The Effects of Temperature and Organism Size on the Feeding Rate and Modeled Chemical Accumulation in Diporeia spp. for Lake Michigan Sediments. Journal of Great Lakes Research 29(1):79-88.

Marsh AG, Manahan DT. 1999. A method for accurate measurements of the respiration rates of marine invertebrate embryos and larvae. Marine Ecology Progress Series 184:1-10.

Mills LS. 2007. Conservation of Wildlife Populations: Demography, Genetics, and Management. Malden: Blackwell Publishing.

Nalepa TF, Hartson DJ, Fanslow DL, Lang GA, Lozano SJ. 1998. Declines in benthic macroinvertebrate populations in southern Lake Michigan, 1980-1993. Canadian Journal of Fisheries and Aquatic Sciences 55(11):2402-2413.

Nalepa TF, Fanslow DL, Foley AJ, III, Lang GA. 2006. Continued disappearance of the benthic amphipod Diporeia spp. in Lake Michigan: is there evidence for food limitation? Canadian Journal of Fisheries and Aquatic Sciences 63(4):872-890.

Pilgrim EM, Scharold JV, Darling JA, Kelly JR. 2009. Genetic structure of the benthic amphipod Diporeia (Amphipoda: Pontoporeiidae) and its relationship to abundance in Lake Superior. Canadian journal of fisheries and aquatic sciences/Journal canadien des sciences halieutiques et aquatiques 66(8):1318-1327.

Quigley MA, Landrum PF, Gardner WS, Stubblefield CR, Gordon WM. 2002. Respiration, Nitrogen Excretion, and O:N Ratios of the Great Lakes Amphipod 'Diporeia' Sp.

R Development Core Team. 2011. R: A Language and Environment for Statistical Computing. Vienna, Austria: R Foundation for Statistical Computing.

Rennie MD, Sprules WG, Johnson TB. 2009. Factors affecting the growth and condition of lake whitefish (Coregonus clupeaformis). Canadian journal of fisheries and aquatic sciences/Journal canadien des sciences halieutiques et aquatiques 66(12):20962108.

Sahoo P, Ananthanarayanan R, Malathi N, Rajiniganth MP, Murali N, Swaminathan P. 2010. Pulsating potentiometric titration technique for assay of dissolved oxygen in water at trace level. Analytica Chimica Acta 669(1-2):17-24. 
Scharold JV, Lozano SJ, Corry TD. 2004. Status of the Amphipod Diporeia spp. in Lake Superior, 1994-2000. Journal of Great Lakes Research 30:360-368.

Stimpson W. 1870. On the Deep-Water Fauna of Lake Michigan. The American Naturalist 4(7):403-405.

Thomann RV, Connolly JP, Parkerton T. 1992. An equilibrium model of organic chemical accumulation in aquatic food webs with sediment interaction. Environmental Toxicology and Chemistry 11(5):615-629.

Vanderploeg HA, Nalepa TF, Jude DJ, Mills EL, et al. 2002. Dispersal and emerging ecological impacts of Ponto-Caspian species in the Laurentian Great Lakes. Canadian Journal of Fisheries and Aquatic Sciences 59(7):1209-1228.

Winnell MH, White DS. 1984. Ecology of shallow and deep water populations of Pontoporeia hoyi (Smith) (Amphipoda) in Lake Michigan. FRESHWAT. INVERTEBR. BIOL. 3(3):118138. 



\title{
CHAPTER 3. Measuring the Effects of Food Availability on Lake Superior Diporeia Consumption Rates Using Radiolabeled Algae
}

\begin{abstract}
Within Lake Superior benthic macroinvertebrate communities, Diporeia are the most abundant organism and account for the largest proportion of biomass. They are also a favored prey for lake whitefish and other benthivorous species. As detritivores that feed on organic material in surficial sediments, Diporeia play a major role in transferring energy and nutrients to higher trophic level consumers. The objective of this study is to model the response of Diporeia consumption rate to changes in food availability. Diporeia were introduced to microcosms containing various concentrations of ${ }^{14} \mathrm{C}$-labeled green algae (Selenastrum capricornutum), and were held for 24 hour durations. Consumption was calculated as the radioisotope content of each animal divided by the specific activity of the labeled algae. The predicted consumption rate corresponding to average Lake Superior algal carbon fluxes was $0.08 \pm \mathrm{SE} \mathrm{mgC} \cdot \mathrm{gDW}^{-1} \cdot \mathrm{d}^{-1}$. The hyperbolic Michaelis-Menten function estimated the maximum consumption rate to be $1.76 \pm \mathrm{SE} \mathrm{mgC} \cdot \mathrm{gDW}^{-1} \cdot \mathrm{d}^{-1}$. The rate at which consumption increased at a normal range of food availability for Lake Superior populations was best explained through linear regression. The parameter estimates presented here may act as inputs for a bioenergetics model used to predict Diporeia growth and production in Lake Superior.
\end{abstract}

The material contained in this chapter will be submitted to the Journal of Great Lakes Research. 


\section{INTRODUCTION}

The fate of algae settling into the cold, hypolimnetic water of Lake Superior is often determined by benthic amphipods of the genus Diporeia spp., formerly known as Pontoporeia hoyi (Bousfield 1989) and herein referred to as Diporeia. Diporeia are detritivores that typically burrow and feed in surficial sediments (Marzolf 1965; Fitzgerald and Gardner 1993). Within Lake Superior benthic macroinvertebrate communities, Diporeia are the most abundant organism and account for the largest proportion of biomass (Auer and Kahn 2004; Sierszen et al. 2006; Auer et al. 2013). They are also a favored prey for lake whitefish and other benthivorous species. Lake Superior Diporeia are nutrient rich organisms, having an overall average lipid content of $32 \%$ (Auer et al. 2009) throughout most of the year, and almost $50 \%$ following spring phytoplankton blooms (Cavaletto et al. 1996). This high lipid content makes them capable of efficiently recycling nutrients and energy to predators. Gardner et al. (1985) estimated that this macroinvertebrate species is responsible for consuming nearly $30 \%$ of the total bioavailable organic matter that has settled to the hypolimnion in Lake Michigan. Of that $30 \%$, only about $9 \%$ is used by Diporeia for metabolic processes, resulting in approximately $21 \%$ being available to secondary consumers through Diporeia biomass (Fitzgerald and Gardner 1993).

The relationship between Diporeia and their predators has been extensively studied (Flint 1986; Owens and Dittman 2003; Hondorp et al. 2005; Rennie et al. 2009; Pothoven et al. 2011), yet estimates of Diporeia consumptive demand are still relatively uncertain (Dermott and Corning 1988; Fitzgerald and Gardner 1993; Lozano et al. 2003). Consumption rates for this amphipod are dependent on several 
factors. Diporeia are intermittent feeders that exhibit full guts most often during spring algae blooms (Quigley 1988; Evans et al. 1990). Quigley and Vanderploeg (1991) showed that Diporeia feeding rates increased with decreasing food quality. When organisms were fed Melosira, a diatom that is considered to be a highly desirable energy source to Diporeia, the nutritional requirements of each individual was assumed to be met faster, leading to an overall decrease in the amount of food consumed (Quigley and Vanderploeg 1991). The amount an individual consumes is also regulated by its size. Quigley (1988) found that juvenile Diporeia had fuller guts than adults that had reached reproductive maturation. Lozano et al. (2003) proposed a model that related Diporeia consumption to body size and water temperature. In order to measure consumption, this group observed fecal pellet production and assumed that the egestion rate was equal to the ingestion rate due to the low percentage of carbon (approximately 1\%) in the sediment. Lozano et al. (2003) found that smaller organisms have fuller guts and feed more continuously than larger individuals.

Since Diporeia have been shown to be important in detrital uptake and transfer of organic carbon, factors influencing consumption rates for this species in Lake Superior play key roles in energy flow and community dynamics. The intensified feeding rate observed during phytoplankton blooms and the subsequent increase in average lipid content of amphipods are indications of Diporeia consumption rates being strongly dependent on carbon inputs to the hypolimnion during the spring. If amphipod biomass in Lake Superior is regulated by food availability, we hypothesize that any change in the flux of organic carbon to the 
benthic community will result in varying the amount of carbon consumed by Diporeia. To test this hypothesis, we investigated the dietary response of Lake Superior Diporeia to a range of food availability conditions through a series of laboratory experiments. The amount of food consumed was evaluated using radioisotopes to label algal cells. This method of measuring Diporeia consumption rates through radiolabeled algae was first implemented by Fitzgerald and Gardner (1993), who introduced Diporeia from Lake Michigan to a concentration of algal carbon typical to ambient conditions. Here, we have added a range of algal carbon concentrations to Diporeia microcosms in order to investigate the relationship between food supply and uptake.

\section{MATERIALS AND METHODS}

\section{Collection and Maintenance of Benthic Communities}

Sediment and live Diporeia were collected from the slope region of Lake Superior (70 m depth site located approximately $5 \mathrm{~km}$ offshore on the western coast of the Keweenaw Peninsula, Michigan, USA ) during 2012 and 2013 using a PONAR grab $\left(\right.$ area $\left.=0.046 \mathrm{~m}^{2}\right)$. Samples were placed into plastic bins with surface water (approximately $8^{\circ} \mathrm{C}$ ) from the collection site and transported back to the laboratory where they were stored in constant darkness at $4^{\circ} \mathrm{C}$. Additional surface water was collected and stored at $4^{\circ} \mathrm{C}$ until used for feeding experiments or for changing Diporeia culture water. 


\section{Preparation of radiolabeled algae}

Carbon uptake was measured through the use of radiolabeled sodium bicarbonate $\left(\mathrm{NaH}^{14} \mathrm{CO}_{3}\right)$. A culture of green algae, Selenastrum capricornutum, was grown and maintained at $20^{\circ} \mathrm{C}$ in an incubator under constant light. This algal species was chosen because of how fast and easily it can be grown, and preliminary experiments showed that it is readily consumed by Diporeia. We transferred $600 \mathrm{~mL}$ of the algal culture into a $1 \mathrm{~L}$ Erlenmeyer flask, split the culture into two separate 300 $\mathrm{mL}$ aliquots, and inoculated one with $\mathrm{NaH}^{14} \mathrm{CO}_{3}$ at an activity of $0.3 \mu \mathrm{Ci} \cdot \mathrm{mL}^{-1}$. This flask was thoroughly agitated to ensure the radioisotopes had been mixed throughout the algae. Both the radiolabeled culture and the non-radioactive control culture were incubated at saturating light intensity $\left(600-800 \mu \mathrm{E} \cdot \mathrm{m}^{-2} \cdot \mathrm{s}^{-1}\right)$ at $20^{\circ} \mathrm{C}$ for 48 hours to irradiate the cells. This time period was chosen based on experiments in which a culture of S. capricornutum was inoculated with $\mathrm{NaH}^{14} \mathrm{CO}_{3}$ and monitored over seven days to determine when radiation levels of the algal cells reached a plateau (Figure 3.1). After this 48 hour period, the two cultures were transferred to a $4^{\circ} \mathrm{C}$ incubator in constant darkness for 24 hours. Each culture was then centrifuged at 2,000 RPMs for 10 minutes. The supernate was extracted, and the remaining algae were then rinsed with deionized water (Milli-Q, Millipore) and centrifuged a second time. Again, we removed the overlying water and added deionized water to each culture until a volume of $100 \mathrm{~mL}$ was reached. The two cultures were stored in $300 \mathrm{~mL}$ Erlenmeyer flasks at $4^{\circ} \mathrm{C}$ until processing for specific activity. 


\section{Determining specific activity of radiolabeled algae}

We filtered five replicates of $0.1 \mathrm{~mL}(0.45 \mu \mathrm{m}$ pore size, $25 \mathrm{~mm}$ diameter $)$ of the radiolabeled algae before and after consumption trials. Filters were transferred into $20 \mathrm{~mL}$ scintillation vials and approximately three to four drops of $0.2 \mathrm{~N} \mathrm{HCl}$ was added to each to remove any inorganic carbon present. The vials were then airdried under a fume hood for 24 hours. Once dried, scintillation cocktail (Scintiverse BD Cocktail, Fisher Scientific) was added to each vial and radioactivity was measured using a Beckman Coulter LS 6500 Multi-Purpose Scintillation Counter.

In order to determine the organic carbon content of the algae, we filtered $1.0 \mathrm{~mL}$ of the control culture using ashed $0.7-\mu \mathrm{m}$ GF/F filters. A few drops of $0.2 \mathrm{~N} \mathrm{HCl}$ were again added to remove inorganic carbon. Filters were then kept frozen until analyzed for particulate organic carbon (POC) content. The specific activity, as described by Conover and Francis (1973), of the radiolabeled algae is calculated as:

$$
S A=\left(\frac{R A}{[C] \times V}\right)
$$

where SA is the calculated specific activity (mgC/DPM), RA is the radioactivity (DPM) of the ${ }^{14} \mathrm{C}$-labeled algae that was filtered, $[\mathrm{C}]$ is the concentration $\left(\mathrm{mgC} \cdot \mathrm{L}^{-1}\right)$ of algal particulate organic carbon as measured from the control, and $\mathrm{V}$ is the volume $(\mathrm{L})$ of labeled algae that was filtered.

To ensure that the control culture was representative of the radiolabeled culture for determining carbon content, we extracted $600 \mathrm{~mL}$ of algae and split it into two $300 \mathrm{~mL}$ parts without adding $\mathrm{NaH}^{14} \mathrm{CO}_{3}$ to either. These two parts were centrifuged twice, combined into a $100 \mathrm{~mL}$ culture as described above, and each 
measured for turbidity. This process was done in triplicate, and the two parts from each experiment never differed by more than 1.0 NTU. It was therefore assumed that the turbidity readings for the control culture could be used to estimate the concentration of organic carbon in the radiolabeled culture for each consumption trial.

\section{Assessing consumption through radioisotope content}

Microcosms were prepared by filling BOD bottles with filtered lake water (0.7$\mu \mathrm{m}$ GF/F filters) and varying amounts of radiolabeled algae. The amount of radiolabeled algae added to each bottle was determined by measuring the turbidity (NTU) of the control culture to estimate the concentration $\left(\mathrm{mgC} \cdot \mathrm{L}^{-1}\right)$ of organic carbon in the radiolabeled culture (Figure 3.2). After the algae and water were added, the bottles were stored in $4^{\circ} \mathrm{C}$ for 24 hours to allow the algae to settle. Two series of trials were performed; the first series (herein referred to as 1D) had one Diporeia added to each $60 \mathrm{~mL}$ BOD bottle. The second series (herein referred to as 5D) had five Diporeia added to each $300 \mathrm{~mL}$ bottle. After either one or five individuals were transferred, bottles were capped with no air space in order to prevent the animals from becoming trapped at the water surface. After 24 hours, Diporeia were removed from the bottles, gently rinsed with water, and measured to the nearest $0.5 \mathrm{~mm}$ under a dissecting microscope. Animals were then transferred into a scintillation vial and air dried for 48 hours. Once dried, Diporeia were ground up using a metal spatula. Each vial had $10 \mathrm{~mL}$ of cocktail added to it and was shaken vigorously before being assessed for radioisotope content. For the 5D trials, the animals were dried, pulverized and homogenized as a group in scintillation 
cocktail. Only a portion of the cocktail was then assayed for radioactivity in order to reduce the effects of quenching. Consumption rates $\left(\mathrm{mgC} \cdot \mathrm{gDW}^{-1} \cdot \mathrm{d}^{-1}\right)$ were calculated as:

$$
\text { Measured Consumption }=\left(\frac{R D}{S A \times D W}\right)
$$

where RD is the radioactivity (DPM) observed in Diporeia biomass and DW is the estimated Diporeia dry weight $(\mathrm{g})$ based on the length of each animal. A lengthweight relationship was developed using a total of 59 Diporeia. Animals were measured for total body length from the tip of the rostrum to the tip of the telson following the gut line, using the computer software Image-Pro Plus 7.0. Individuals were then dried at $60^{\circ} \mathrm{C}$ for 24 hours and weighed to the nearest $0.001 \mathrm{mg}$.

To ensure that radioactivity levels represented the effects of consumption, and that there were no radiolabeled algal cells fortuitously attached to the exoskeleton of test animals, we placed dead individuals into bottles containing the same amounts of radiolabeled algae as in each trial. These animals were left for 24 hours and processed as described above. In order to determine the duration of each experiment, Diporeia were fed $0.5 \mathrm{mg}$ of radiolabeled algal carbon, as described above, and were kept at $4^{\circ} \mathrm{C}$ in the dark for $12,24,48,72,96$, and 168 hours. No change in activity levels (DPM) were observed after 24 hours. We therefore limited all subsequent trials to this 24 hour time period.

\section{Statistical Analysis}

Data collected from this study were analyzed using linear and nonlinear regression. Model coefficients were determined in the statistical software program $\mathrm{R}$ 
(R Development Core Team 2011) and significance evaluated at $\alpha=0.05$. All coefficients were determined using the mean consumption rate among replicates in 1D and 5D trials. A variance-weighted statistical analysis was performed on the nonlinear regression to determine goodness of fit for the model.

\section{RESULTS}

We collected 102 data entries for Lake Superior Diporeia feeding rate. Of the 330 individuals used in these experiments, most were processed in groups of five (285 animals). All others were processed individually (45 animals). Experimental conditions were consistent among all trials and only varied in concentrations of food available to each animal and with bottle size between the 1D and 5D trials. The size distribution of Diporeia in this study was uniform. Average animal length among all trials was $4.82 \mathrm{~mm}$ with a standard error of $0.04 \mathrm{~mm}$.

Consumption rates ranged from 0.01 to $1.24 \mathrm{mgC} \cdot \mathrm{gDW}^{-1} \cdot \mathrm{d}^{-1}$, and increased asymptotically with increasing concentrations of algal carbon (Figure 3.3). The more rapid change at low carbon concentrations was consistent among all trials. The relationship between consumption rate and organic carbon flux was described for both $1 \mathrm{D}$ and $5 \mathrm{D}$ trials, as well as all trials combined, using the Michaelis-Menten equation:

$$
\text { Consumption }_{\text {Nonlinear model }}=C_{\text {max }} \times\left(\frac{J_{P O C}}{J_{P O C}+K}\right)
$$

where $\mathrm{C}_{\max }$ is the maximum consumption rate $\left(\mathrm{mgC} \cdot \mathrm{gDW}^{-1} \cdot \mathrm{d}^{-1}\right), \mathrm{J}_{\mathrm{POC}}$ is the flux of organic carbon $\left(\mathrm{mgC} \cdot \mathrm{m}^{-2} \cdot \mathrm{d}^{-1}\right)$, and $\mathrm{K}$ is the half-saturation constant (Table 3.1). The 
data was also analyzed using simple linear regression for lower $\mathrm{J}_{\mathrm{POC}}$ values ( 0 to 350 $\left.\mathrm{mgC} \cdot \mathrm{m}^{-2} \cdot \mathrm{d}^{-1}\right)$. This relationship was described using the equation:

$$
\text { Consumption }_{\text {Linear model }}=b_{1}\left(J_{P O C}\right)
$$

where $b_{0}$ is the intercept of consumption and $b_{1}$ is the rate of consumption increase over a range of $J_{P O C}$ values. This linear function explained a larger proportion of the variability $\left(R^{2}=0.91\right)$ in consumption rate at low $J_{P o c}$ values for the $1 D$ trials $\left(R^{2}=0.96\right), 5 D$ trials $\left(R^{2}=0.96\right)$, and combined data $\left(R^{2}=0.91\right)$. The linear function also had less variance around the parameter estimates (Table 3.1). The $\mathrm{J}_{\mathrm{POC}}$ stimulated consumption values show a $\mathrm{R}^{2}$ of 0.91 to observed values and are significant $(p<0.001)$

Specific activity of the algal cultures did not vary significantly (student t-test, $p<0.01$ ) between measurements taken before and after each trial. DPM values of Diporeia that were dead before being introduced to BOD bottles were within background levels.

\section{DISCUSSION}

\section{Overall model performance and assessment}

The true relationship between consumption rate and carbon flux is inadequately described by a simple linear function since feeding is limited by animal size. Instead, this relationship can be defined by the form of the Michaelis-Menten equation (Eq. 3.3) (Barthel 1983). In an oligotrophic system such as Lake Superior, $J_{\text {POC }}$ values are low and fall within the increasing portion of the Michaelis-Menten function. Within this range (between 60 to $90 \mathrm{mgC} \cdot \mathrm{m}^{-2} \cdot \mathrm{d}^{-1}$ ) Diporeia are food 
limited, leading to consumption rates being extremely sensitive to food inputs. At higher carbon-flux conditions, Diporeia are no longer food limited, and so the response of consumption rate to food availability is almost completely discontinued. Between these two $\mathrm{J}_{\mathrm{POC}}$ ranges is considered to be a transitional phase where the response of consumption rate slows as the carbon flux increases. Prior to this transitional phase, (Eq. 3.3) is too restricted by assumption to be of use in describing the relationship between consumption and food availability. The rate at which consumption increases with low $\mathrm{J}_{\mathrm{POC}}$ values is consistently overestimated using the Michaelis-Menten function due to the influence of consumption rates corresponding to extremely high food availability ranges. Therefore, the consumption-carbon flux relationship can best be explained through linear regression (Eq. 3.4). However, parameters calculated for the nonlinear function (Eq. 3.3) are still useful for bioenergetic models (e.g. Bioenergetics 3.0, Ecopath, etc.).

Since consumption is expected to be zero when $\mathrm{J}_{\mathrm{POC}}=0$, we decided to force the linear regression through the origin. Although forcing a zero-intercept can impair a regression, it is necessary in this case since we are interested in possible consumption vales that are within extremely low $\mathrm{J}_{\mathrm{POC}}$ ranges. Seven outliers were removed before performing the regression analyses. These values were identified in our data as being more than three standard deviations away from the mean of the remaining values in each trial. We view the removal of outliers to be a prudent step, as they may seriously skew the least-squares fit of a regression surface, and act as a control on key model properties (Montgomery et al. 2006). Additionally, one 5D trial was removed due to the extremely low results observed in all three of the replicates. 
All results that were removed are shown as either open circles (1D trials) or open diamonds (5D trials) in Figure 3.3a, with the exception of a single consumption value $\left(1.8 \mathrm{mgC} \cdot \mathrm{gDW}^{-1} \cdot \mathrm{d}^{-1}\right)$ at $1125 \mathrm{mgC} \cdot \mathrm{m}^{-2} \cdot \mathrm{d}^{-1}$.

As mentioned earlier in this manuscript, Diporeia do not feed continuously due to their life history strategy of selectively feeding on higher quality food during different periods of the year (Gardner et al. 1985; Dermott and Corning 1988; Cavaletto et al. 1996; Lozano et al. 2003). A comparison of results from 1D and 5D trials shows a difference in sample variance between the two experimental methods. This difference is most clearly demonstrated by the standard error of $\mathrm{K}$ for $1 \mathrm{D}$ trials (SE of $K=82.07)$ being higher than $K(K=79.40)$ (Table 3.1). The SE of $K$ for $5 D$ trials ( $\mathrm{SE}$ of $\mathrm{K}=338.11$ ) was approximately one third of its corresponding $\mathrm{K}(\mathrm{K}=938.77)$ (Table 3.1). Trials with only one individual per bottle resulted in much higher variance in consumption values than the $5 \mathrm{D}$ trials. It was assumed that processing five individuals as a group would diminish the impact of non-feeding individuals on the model. Given the increase in predictive power associated with a decrease in sample variance, the five replicates from each 1D trial were averaged and pooled with the results of the $5 \mathrm{D}$ trials. We rely solely on the combined (1D and $5 \mathrm{D}$ ) data to estimate Diporeia consumption.

Although our results fall in the lower range of previously reported consumption rates for Diporeia, the empirical data from this study is still comparative with these earlier estimates. Using the combined linear model, the predicted consumption rate corresponding to average Lake Superior algal carbon fluxes (75 $\mathrm{mgC} \cdot \mathrm{m}^{-2} \cdot \mathrm{d}^{-1}$ ) (see Baker 1991) is $0.08 \pm \mathrm{SE} \mathrm{mgC} \cdot \mathrm{gDW}^{-1} \cdot \mathrm{d}^{-1}$. Lozano (2003), Harkey 
et al. (1994), and Dermott and Corning (1988) found adult Diporeia consumption rates to be $0.2,0.8$, and $2.6 \mathrm{mgC} \cdot \mathrm{gDW}^{-1} \cdot \mathrm{d}^{-1}$, respectively. These values were adjusted by correcting for the proportion of organic carbon in sediments, wet:dry mass, and amphipod abundance. The consumption model proposed by Lozano et al. (2003) was developed by monitoring fecal pellet production in the laboratory using Lake Michigan Diporeia and with defining water temperature and animal size as independent parameters. Because their experimental study was performed in a controlled environment, we believe it to be a more accurate and precise estimate of Diporeia consumption compared to Harkey et al. (1994) and to Dermott and Corning (1988) who used observational data as an index for consumption and growth.

Dermott and Corning (1988) calculated ingestion rates using intermittent observations of Diporeia gut content. The ingestion rate values they reported were therefore strongly influenced by the environmental conditions and gut contents of Diporeia at the time of their sampling efforts. The application of the carbon-labeling technique used in this study circumvents challenges associated with measuring gut contents of such small organisms.

Since consumption rates were derived from replicated measurements of specific activity (Eq. 3.1) before and after each trial in this study, and not from the absolute quantity of ${ }^{14} \mathrm{C}$, it was assumed that consumption estimates were not affected by algal cell division, bacterial activity in the culture flask, or an uneven distribution of ${ }^{14} \mathrm{C}$ among algal cells. The observed absence of radioisotopes in trials with dead Diporeia shows that all DPM counts in this study are representative of consumption. Animal size in this study (mean length=4.82 $\mathrm{mm}$ ) was taken into 
account by dividing the estimate of carbon consumed $(\mathrm{mgC})$ by the total mass (gDW) of the animals in each trial. Consumption rates for Diporiea have been shown to be size dependent (Lozano et al. 2003). Therefore, predictions of lakewide Diporeia biomass should have considerations of both food availability as well as amphipod size classes.

Another key assumption of this study was that bottle effects were minimal. The experimental animal density for the $1 \mathrm{D}$ and $5 \mathrm{D}$ trials is equivalent to 689 and 1337 Diporeia $\cdot \mathrm{m}^{-2}$, respectively. These conditions approached natural lakewide abundances of Diporeia in Lake Superior (Barbiero et al. 2011; Auer et al. 2013). Similarly, the lower values of carbon fluxes used in this study correspond to natural ratios of algae to animals. In Figure 3.4, the average values for organic carbon fluxes among the Great Lakes are plotted with the average consumption rates (see Meyers 1980; Bloesch 1982; Charlton 1983; Baker 1991; Meyers and Eadie 1993; Urban et al. 2004). In 1D trials, consumption rates continually increased at low values of $\mathrm{J}_{\mathrm{POC}}$, corresponding to a linear function, and then transitioned to decreasing rates of consumption as carbon flux increased (Figure 3.3). The 5D trials also showed this result, but the response was not as pronounced, as demonstrated by values of $K$ corresponding to 1D and 5D (Table 3.1). The half saturation constant, $\mathrm{K}$, describes the efficiency with which Diporeia utilize the available organic carbon. $\mathrm{C}_{\max }$ and $\mathrm{K}$ were greater for the $5 \mathrm{D}$ trials $\left(C_{\max }=1.50, \mathrm{~K}=938.77\right)$ compared to the $1 \mathrm{D}$ trials $\left(C_{\max }=0.36, K=79.40\right)$ (Table 3.1). We attribute this difference to a combination of factors. First, it is possible that animals from the 5D trials had become more starved compared to animals from the $1 \mathrm{D}$ trials. This is due to the fact that $1 \mathrm{D}$ trials were 
performed 24 hours after the animals were collected from Lake Superior, while 5D trials were performed 12,25 , and 37 days after collection. Between collection and the initiation of the 5D trials, animals were kept in natural sediment without additional food supplements. Furthermore, the sediment became fully mixed during transport to the laboratory, which potentially buried a large portion of the organic carbon consumable by Diporeia under the top layer where these animals typically burrow. The mixed sediment and lack of food supplements likely caused amphipods to more readily consume the green algae during consumption trials. Second, consumption rates in the $5 \mathrm{D}$ trials may have been higher due to a more competitive environment within the mircrocosm. An increase in consumption rate due to increases in population densities has been found in multiple other species. For example, Ndegwa (2000) found that feeding rates of Eisenia foetida increased as animal density increased. This increase in feeding observed for $E$. foetida contributed to higher growth and production rates in the population. Third, it was assumed that 24 hours would be sufficient time for Diporiea to acclimate to its new environment based on previous studies (Quigley et al. 2002). However, the potential stress involved with transporting these animals in 1D trials from the lake, to a laboratory culture, and then again to a BOD bottle within a two day time period might have caused them to spend less time foraging for food, and more time attempting to flee from their surroundings.

Quenching (whether chemical, color, dilution, or absorption) was also assumed to have little to no influence on the final results of this study. The effects of quenching were accounted for through an external standard, H\# Plus, that had been previously installed in the scintillation counter used to analyze all samples. 
According to the Operating Manual (1999) for this counter, a quenching agent is detected by the $\mathrm{H \#} \mathrm{Plus} \mathrm{when} \mathrm{the} \mathrm{standard} \mathrm{has} \mathrm{a} \mathrm{variation} \mathrm{of} \mathrm{over} 100$ repeats. H\# repeats among all samples in this study ranged from 50 to 73 . This is an indication that quenching had a relatively minor impact on ${ }^{14} \mathrm{C}$ detection before correction by the external standard. The radioisotope analysis of each sample produced values recorded in both CPM and DPM. Carbon-14 counting efficiency (i.e. CPM/DPM) was approximately $82 \pm 8 \%$, and did not vary significantly among samples of Diporeia and algae. Preliminary experiments showed decreasing ${ }^{14} \mathrm{C}$ counting efficiency as the number of Diporeia $(1,3,5$, or 10 animals per vial) within each sample bottle increased. For this reason, only a fraction of the total animal biomass was assayed in the 5D trials. The concentration of algae on each filter that was assessed for radioisotope content did not have an impact on our estimate of specific activity. This was determined by the direct relationship that was observed between the volume of radiolabeled algae filtered $(0.01 \mathrm{uL}$ to $40 \mathrm{~mL})$ and its resulting DPM value.

\section{Conclusions}

Lake Superior Diporeia consumption rates $\left(\mathrm{mgC} \cdot \mathrm{gDW}^{-1} \cdot \mathrm{d}^{-1}\right)$ responded to food availability, expressed as $\mathrm{J}_{\mathrm{POC}}$ in units of $\mathrm{mg}$ (organic carbon) $\cdot \mathrm{m}^{-2} \cdot \mathrm{d}^{-1}$, according to the linear function:

$$
\text { Consumption }=0.0011\left(J_{P O C}\right)
$$

In order to estimate the theoretical maximum consumption rate, required for bioenergetic model inputs, we used the Michaelis-Menten function (Eq. 3.3). Our findings are consistent with previous studies of Diporeia consumption rates among other Great Lakes. A leading theory for the decline of Diporeia in the lower Great 
Lakes is that populations have experienced decreased food availability. Understanding how Diporeia populations might respond to changes in phytoplankton production may help in predicting future food-web dynamics in Lake Superior. 


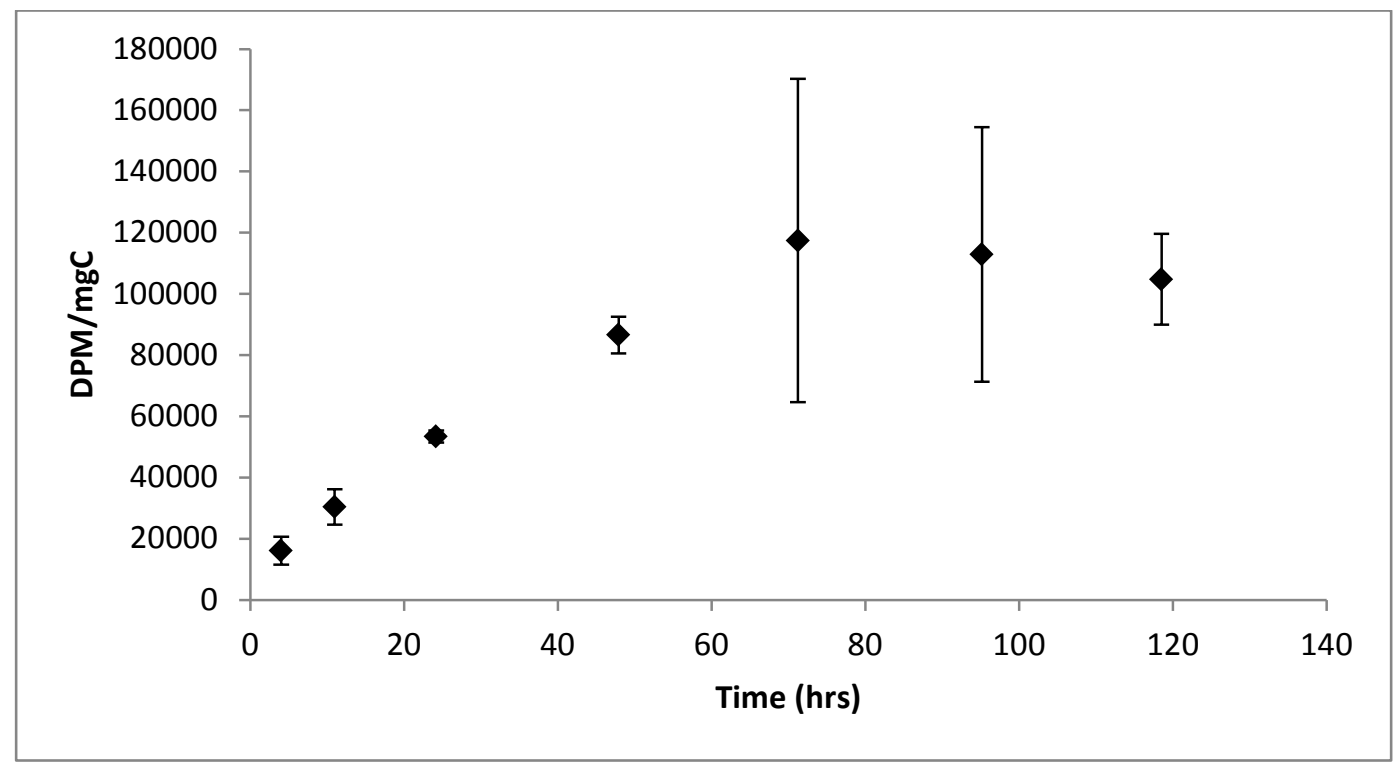

Figure 3.1 Relationship between the average disintegrations per minute (DPM) per milligram of algal carbon and time $( \pm S E)$ for three cultures of green algae $(S$. capricornutum) inoculated with $\mathrm{NaH}^{14} \mathrm{CO}_{3}$ at an activity of $0.1 \mu \mathrm{Ci} \cdot \mathrm{mL}^{-1}$. 


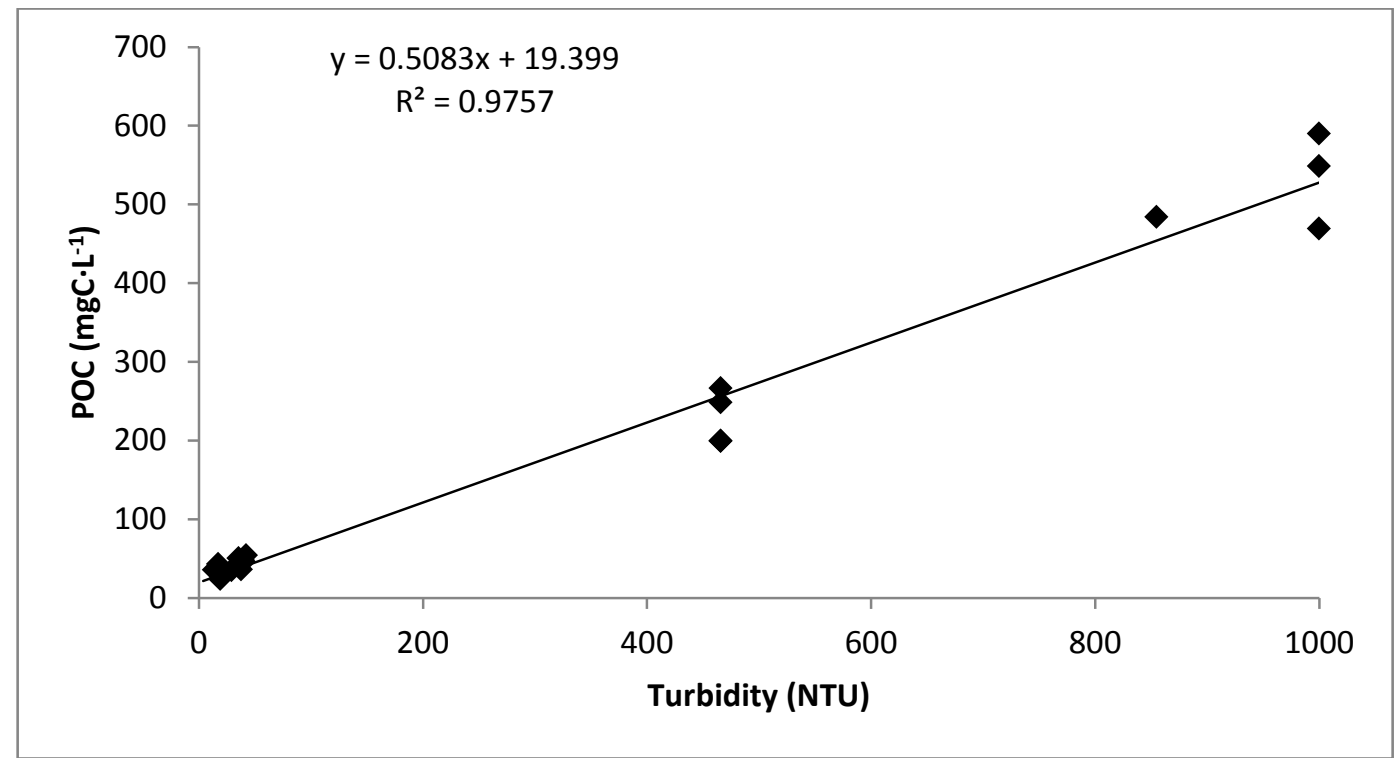

Figure 3.2 Relationship between the measured turbidity of a sample $(n=17)$ of green algae (S. capricornutum) and its particulate organic carbon content (POC). 
a)

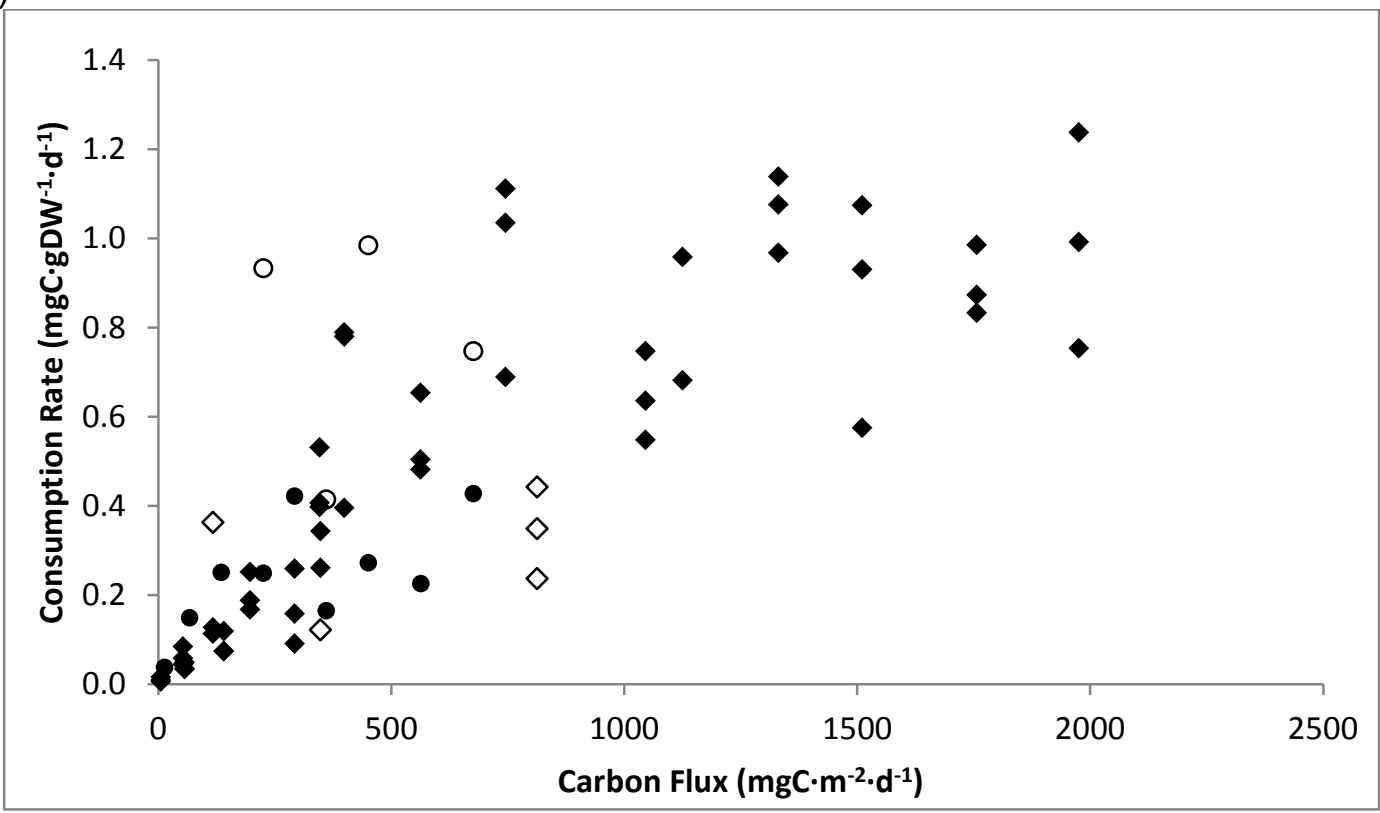

b)

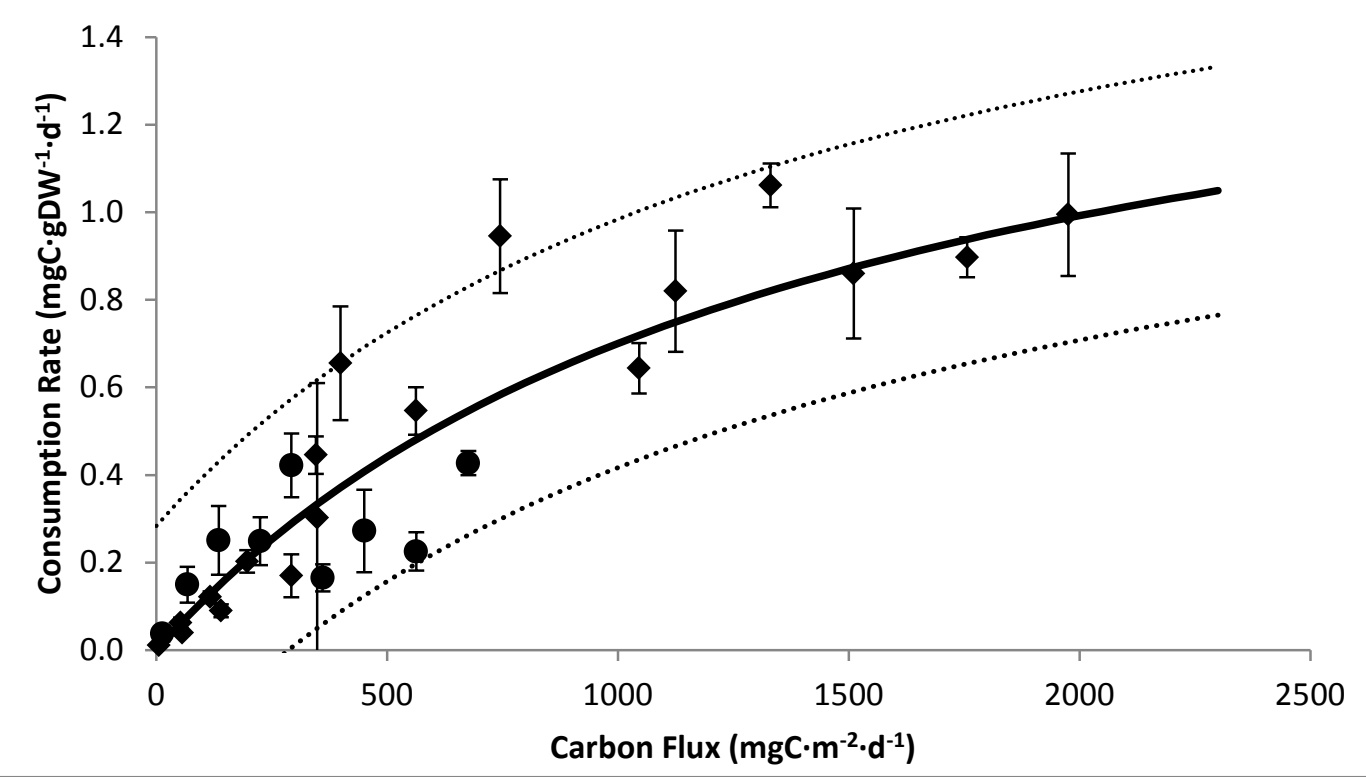

Figure 3.3 Observed consumption rates from feeding trials during June and July 2013 using radiolabeled $S$. capricornutum and either one (1D=circles) or five (5D=diamonds) Diporeia. Open shapes denote outliers. (a) All values from 5D trials plotted with means of 1D trials. (b) Nonlinear model (dashed line represents $95 \%$ confidence interval) showing the relationship between consumption rate (mean $\pm \mathrm{SE}$ ) and organic carbon flux ( $\left.\mathrm{J}_{\mathrm{POC}}\right)$. 


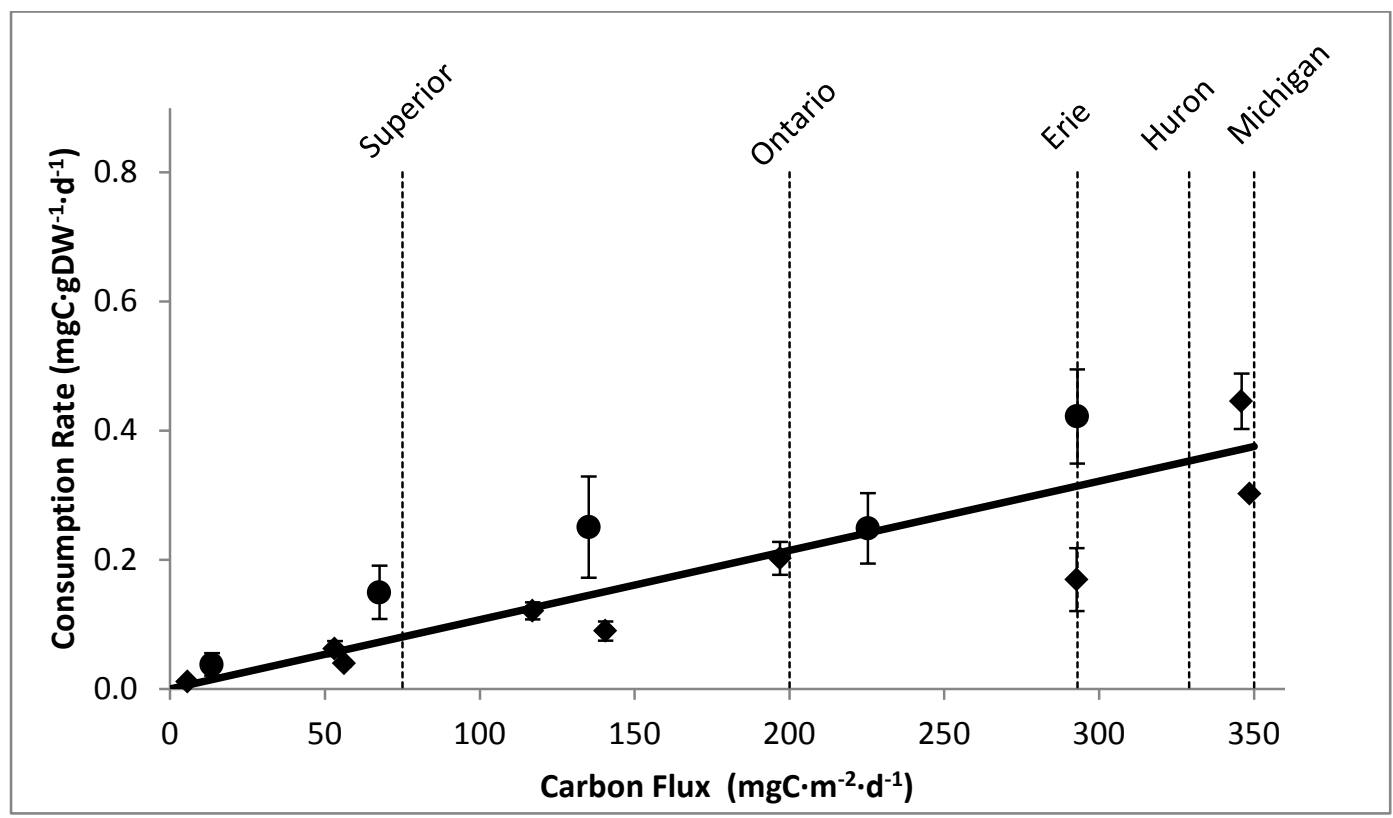

Figure 3.4 Linear relationship for Diporeia consumption rates $( \pm S E)$ within the natural range $(<350)$ of organic carbon fluxes $\left(\mathrm{J}_{\mathrm{POC}}\right)$ in the Great Lakes. The vertical dashed lines correlate to literature values for $J_{P O C}$ in the each of the Great Lakes (Meyers 1980; Bloesch 1982; Charlton 1983; Baker 1991; Meyers and Eadie 1993; Urban et al. 2004). $\left(R^{2}=0.91, p<0.0001\right)$ 
Table 3.1 Parameter estimates for six equations predicting Diporeia consumption $\left(\mathrm{mgC} \cdot \mathrm{gDW}^{-1} \cdot \mathrm{d}^{-1}\right)$ from food availability (i.e. organic carbon flux; $\mathrm{J}_{\mathrm{POC}}$ ). The linear models (a) predict consumption at low $\mathrm{J}_{\mathrm{POC}}$ values, while the nonlinear models (b) describe the response of consumption to food availability at high $\mathrm{J}_{\mathrm{POC}}$ values. Parameter calculations were made for each model based on the experimental method used (i.e. individual and combined for 1D and 5D trials).

a)

\begin{tabular}{cccc}
\hline \multicolumn{4}{c}{ Linear Model $\left(\mathrm{J}_{\text {POC }}<\mathbf{3 5 0}\right)$} \\
\hline Trial(s) & $1 \mathrm{D}$ & $5 \mathrm{D}$ & Combined \\
Equation & Eq.4 & Eq.4 & Eq.4 \\
slope, $\mathbf{b}_{\mathbf{1}}$ & 0.0014 & 0.0008 & 0.0011 \\
$\mathrm{SE} \mathrm{of} \mathbf{b}_{\mathbf{1}}$ & 0.0001 & 0.0001 & 0.0001 \\
$\mathbf{R}^{\mathbf{2}}$ & 0.96 & 0.96 & 0.91 \\
Degrees of Freedom & 4 & 9 & 13 \\
\hline
\end{tabular}

b)

\begin{tabular}{cccc}
\hline \multicolumn{4}{c}{ Nonlinear Model (All J Joc Values) } \\
\hline Trial & $1 \mathrm{D}$ & $5 \mathrm{D}$ & Combined \\
\hline Equation & Eq.3 & Eq.3 & Eq.3 \\
C $_{\max }$ & 0.36 & 1.50 & 1.76 \\
\hline SE of $\boldsymbol{C}_{\max }$ & 0.09 & 0.26 & 0.40 \\
\hline $\mathbf{K}$ & 79.40 & 938.77 & 1427.26 \\
\hline SE of K & 82.07 & 338.11 & 550.75 \\
SE of Residuals & 0.09 & 0.13 & 0.14 \\
\hline Degrees of Freedom & 4 & 16 & 25 \\
\hline
\end{tabular}




\section{REFERENCES}

Auer MT, Auer NA, Urban NR, Auer T. 2013. Distribution of the Amphipod Diporeia in Lake Superior: The Ring of Fire. Journal of Great Lakes Research(0).

Auer NA, Kahn JE. 2004. Abundance and Distribution of Benthic Invertebrates, with Emphasis on Diporeia, along the Keweenaw Peninsula, Lake Superior. Journal of Great Lakes Research 30(Supplement 1):340-359.

Auer NA, Cannon BA, Auer MT. 2009. Life History, Distribution, and Production of Diporeia Near the Keweenaw Peninsula Lake Superior. Journal of Great Lakes Research 35(4):579-590.

Baker JE. 1991. Sediment trap fluxes and benthic recycling of organic carbon, polycyclic aromatic hydrocarbons, and polychlorobiphenyl congeners in Lake Superior. Environmental Science \& Technology 25(3):500.

Barbiero RP, Schmude K, Lesht BM, Riseng CM, Warren GJ, Tuchman ML. 2011. Trends in Diporeia populations across the Laurentian Great Lakes, 1997-2009. Journal of Great Lakes Research 37(1):9-17.

Barthel KG. 1983. Food uptake and growth efficency of Eurytemora affinis (Copepoda: Calanoida). Marine biology. Berlin, Heidelberg 74(3):269-274.

Bloesch J. 1982. Inshore-offshore sedimentation differences resulting from resuspension in the eastern basin of Lake Erie. Canadian Journal of Fisheries and Aquatic Sciences 39(5):748.

Bousfield EL. 1989. Revised morphological relationships within the amphipod genera Pontoporeia and Gammaracanthus and the "glacial relict" significance of their postglacial distributions. Canadian Journal of Fisheries and Aquatic Sciences 46(10):1714-1725.

Cavaletto JF, Nalepa TF, Dermott R, Gardner WS, Quigley MA, Lang GA. 1996. Seasonal variation of lipid composition, weight, and length in juvenile Diporeia spp. (Amphipoda) from Lakes Michigan and Ontario. Canadian Journal of Fisheries and Aquatic Sciences 53(9):2044-2051.

Charlton MN. 1983. Downflux of sediment, organic matter, and phosphorus in the Niagara River area of Lake Ontario. Journal of Great Lakes Research 9(2):201.

Conover R, Francis V. 1973. The use of radioactive isotopes to measure the transfer of materials in aquatic food chains. Marine Biology 18(4):272-283.

Coulter B. 1999. LS 6500 Scintillation System Operating Manual. Fullerton, CA: Beckman Coulter, Inc.

Dermott R, Corning K. 1988. Seasonal ingestion rates of Pontoporeia hoyi (Amphipoda) in Lake Ontario. Canadian Journal of Fisheries and Aquatic Sciences 45(11):1886-1895.

Evans MS, Quigley MA, Wojcik JA. 1990. Comparative Ecology of Pontoporeia Hoyi Populations in Southern Lake Michigan: The Profundal Region Versus the Slope and Shelf Regions. Journal of Great Lakes Research 16(1):27-40.

Fitzgerald SA, Gardner WS. 1993. An algal carbon budget for pelagic-benthic coupling in Lake Michigan. Limnology and Oceanography 38(3):547-560. 
Flint RW. 1986. Hypothesized Carbon Flow through the Deepwater Lake Ontario Food Web. Journal of Great Lakes Research JGLRDE Vol. 12, No. 4, p 344-354, 1986. 2 fig, 2 tab, 55 ref.

Gardner WS, Nalepa TF, Frez WA, Cichocki EA, Landrum PF. 1985. Seasonal patterns in lipid content of Lake Michigan macroinvertebrates. Canadian Journal of Fisheries and Aquatic Sciences 42(11):1827-1832.

Harkey GA, Lydy MJ, Kukkonen J, Landrum PF. 1994. Feeding selectivity and assimilation of PAH and PCB in Diporeia spp. Environmental Toxicology and Chemistry 13(9):14451455.

Hondorp DW, Pothoven SA, Brandt SB. 2005. Influence of Diporeia Density on Diet Composition, Relative Abundance, and Energy Density of Planktivorous Fishes in Southeast Lake Michigan. Transactions of the American Fisheries Society 134(3):588-601.

Lozano SJ, Gedeon ML, Landrum PF. 2003. The Effects of Temperature and Organism Size on the Feeding Rate and Modeled Chemical Accumulation in Diporeia spp. for Lake Michigan Sediments. Journal of Great Lakes Research 29(1):79-88.

Marzolf GR. 1965. Substrate Relations of the Burrowing Amphipod Pontoporeia Affinis in Lake Michigan. Ecology 46(5):580-592.

Meyers PA. 1980. Fatty acid and hydrocarbon content of settling sediments in Lake Michigan. Journal of Great Lakes Research 6(4):331.

Meyers PA, Eadie BJ. 1993. Sources, degradation and recycling of organic matter associated with sinking particles in Lake Michigan. Organic Geochemistry 20(1):47-56.

Montgomery DC, Peck EA, Vining GG. 2006. Introduction to linear regression analysis. Wiley.

Ndegwa PM. 2000. Effects of stocking density and feeding rate on vermicomposting of biosolids. Bioresource technology 71(1):5.

Owens RW, Dittman DE. 2003. Shifts in the Diets of Slimy Sculpin (Cottus cognatus) and Lake Whitefish ( Coregonus clupeaformis) in Lake Ontario Following the Collapse of the Burrowing Amphipod Diporeia. Aquatic Ecosystem Health \& Management 6(3):311-323.

Pothoven SA, Hondorp DW, Nalepa TF. 2011. Declines in deepwater sculpin Myoxocephalus thompsonii energy density associated with the disappearance of Diporeia spp. in lakes Huron and Michigan. Ecology of Freshwater Fish 20(1):14-22.

Quigley MA. 1988. Gut Fullness of the Deposit-Feeding Amphipod, Pontoporeia hoyi, in Southeastern Lake Michigan. Journal of Great Lakes Research JGLRDE Vol. 14, No. 2, p 178-187, 1988. 5 fig, 1 tab, 58 ref.

Quigley MA, Vanderploeg HA. 1991. Ingestion of live filamentous diatoms by the Great Lakes amphipod, Diporeia sp.: A case study of the limited value of gut contents analysis. SEVENTH INTERNATIONAL COLLOQUIUM ON AMPHIPODA PROCEEDINGS.

Quigley MA, Landrum PF, Gardner WS, Stubblefield CR, Gordon WM. 2002. Respiration, Nitrogen Excretion, and O:N Ratios of the Great Lakes Amphipod 'Diporeia' Sp.

R Development Core Team. 2011. R: A Language and Environment for Statistical Computing. Vienna, Austria: R Foundation for Statistical Computing.

Rennie MD, Sprules WG, Johnson TB. 2009. Factors affecting the growth and condition of lake whitefish (Coregonus clupeaformis). Canadian journal of fisheries and aquatic 
sciences/Journal canadien des sciences halieutiques et aquatiques 66(12):20962108.

Sierszen ME, Peterson GS, Scharold JV. 2006. Depth-specific patterns in benthic-planktonic food web relationships in Lake Superior. Canadian Journal of Fisheries and Aquatic Sciences 63(7):1496-1503.

Urban NR, Lu X, Chai Y, Apul DS. 2004. Sediment trap studies in Lake Superior; insights into resuspension, cross-margin transport, and carbon cycling. Journal of Great Lakes Research 30:147-161. 